\title{
Microalgal Reactors: A Review of Enclosed System Designs and Performances
}

\author{
Ana P. Carvalho, Luís A. Meireles, and F. Xavier Malcata* \\ Escola Superior de Biotecnologia, Universidade Católica Portuguesa, Rua Dr. António Bernardino de Almeida, P-4200-072 \\ Porto, Portugal
}

\begin{abstract}
One major challenge to industrial microalgal culturing is to devise and develop technical apparata, cultivation procedures and algal strains susceptible of undergoing substantial increases in efficiency of use of solar energy and carbon dioxide. Despite several research efforts developed to date, there is no such thing as "the best reactor system"- defined, in an absolute fashion, as the one able to achieve maximum productivity with minimum operation costs, irrespective of the biological and chemical system at stake. In fact, choice of the most suitable system is situationdependent, as both the species of alga available and the final purpose intended will play a role. The need of accurate control impairs use of open-system configurations, so current investigation has focused mostly on closed systems. In this review, several types of closed bioreactors described in the technical literature as able to support production of microalgae are comprehensively presented and duly discussed, using transport phenomenon and process engineering methodological approaches. The text is subdivided into subsections on: reactor design, which includes tubular reactors, flat plate reactors and fermenter-type reactors; and processing parameters, which include gaseous transfer, medium mixing and light requirements.
\end{abstract}

\section{Contents}

\begin{tabular}{|ll|}
\hline 1. Introduction & 1490 \\
2. Reactor design & 1492 \\
2.1. Tubular reactors & 1492 \\
2.1.1. Vertical tubular reactors & 1492 \\
2.1.2. Horizontal tubular reactors & 1493 \\
2.1.3. Helical tubular reactors & 1494 \\
2.1.4. $\alpha-$ Shaped reactors & 1494 \\
2.2. Flat plate reactors & 1495 \\
2.3. Fermenter-type reactors & 1496 \\
3. Processing parameters & 1496 \\
3.1. Gaseous transfer & 1496 \\
3.1.1. Carbon source & 1496 \\
3.1.2. Transport process & 1497 \\
3.1.3. CO transfer systems & 1498 \\
3.1.4. O removal & 1500 \\
3.2. Mixing & 1501 \\
3.3. Light requirement & 1502 \\
4. Conclusions & 1503 \\
\hline
\end{tabular}

\section{Introduction}

From an economic point of view, microalgae may be described as microorganisms with the ability to "harvest the sun" and hence transform its radiant energy into valuable products, at the expense of (theoretically) inexpensive natural resources (viz., $\mathrm{CO}_{2}$ and $\mathrm{H}_{2} \mathrm{O}$ ). The idea of producing microalgae at the technical scale first occurred to German scientists, in concerted attempts to devise inexpensive sources of protein able

* To whom correspondence should be addressed. Tel: 351225580004 . Fax: 351225090 351. Email: fxmalcata@esb.ucp.pt. to replace those from animal sources, which were difficult to obtain during World War II (1). In the U.S., research on mass culture of microalgae began as a collateral development of fundamental studies on photosynthesis; in attempts to translate the biological requirements of microalgal culture into engineering specifications, a large-scale culture plant was made at Stanford Research Institute, back in 1948. During 1951, Arthur D. Little, Inc. (Cambridge, MA) made further advances through construction and operation of a Chlorella pilot plant for the Carnegie Institution (2). Other studies followed in Japan, under the guidance of Tamiya (2). Although experimental results showed that continuous culture was possible, many subjects still needed improvement, as microalgal proteins could not compete with such inexpensive plant sources as soybean meal.

Other developments were achieved by Oswald, who started studying the role of microalgal photosynthesis in ponds and accordingly developed a high-rate algal pond for photosynthetic wastewater treatment. In the 1960s, Nichoporovich and Semenenko intensively studied closed culture systems, for extraterrestrial life support during prolonged missions in outer space; this subject also received considerable attention by NASA (1). The advent of the oil crisis in the 1970s led researchers to investigate microalgae as potential sources of biomass, aiming at methane production (3); more recently, advances have focused on the production of fine chemicals and secondary metabolites, which may reach high prices in the world market.

The evolution in goals throughout time has therefore been driven by two major streamlines: (i) requirement for alternative sources of several products, which were scarce as a result of political or economic reasons; and (ii) perception that microalgal-mediated processes (as happens with most biotechnological ones) are usually characterized by noncompetitive production costs, the economic feasibility of which relies heavily on the market value of the resulting compounds. As expected, the 
Table 1. Generic Description of Commercial Microalgal Culture Systems Currently in Use

\begin{tabular}{|c|c|c|c|c|}
\hline microorganism & metabolite & commercial use & culturing system & location \\
\hline Chlorella spp. & astaxanthin & pigmenting agent & $\begin{array}{l}\text { circular ponds with } \\
\text { rotating arm }\end{array}$ & $\begin{array}{l}\text { Taiwan, Japan, } \\
\text { U.S., Thailand }\end{array}$ \\
\hline & ferredoxin & laboratory use & $\begin{array}{l}\text { raceway ponds } \\
\text { fermenters (heterotrophic) }\end{array}$ & \\
\hline Dunaliella salina & $\beta$-carotene & pigmenting agent & $\begin{array}{l}\text { extensive open ponds } \\
\text { raceway ponds }\end{array}$ & $\begin{array}{l}\text { Australia, China, India, } \\
\text { Chile, U.S., Israel }\end{array}$ \\
\hline Euglena gracilis & arachidonic acid & laboratory use & & \\
\hline Haematococcus pluvialis & astaxanthin & pigmenting agent & & U.S. \\
\hline Isochrysis galbana & docosahexaenoic acid & functional food additive & & \\
\hline Phaeodactylum tricornutum & eicosapentaenoic acid & medical use & & \\
\hline Spirulina platensis & phycocyanin & food coloring & & \\
\hline Crypthecodinium cohnii & docosahexaenoic acid & functional food additive & fermenters (heterotrophic) & U.S. \\
\hline
\end{tabular}

nature of these compounds has evolved with time, in response to changing market demands.

A broad list of applications of microalga cultures has been described and discussed in the literature. Those that have attained commercial expression encompass the areas of healthy foods, food additives, pigments, diets for aquaculture, growth-regulating agents, secondary metabolites and wastewater treatments $(4,5)$ (see Table 1). The production of several bioactive compounds such as hydrocarbons, isotopes, polysaccharides, and antifungal, antitumor, antibacterial and antiviral substances is currently under study; uses of microalgae for $\mathrm{CO}_{2}$ fixation, removal of nitric oxide from flue gas, fuel production, recovery of heavy metals from effluents and in outer space technologies are also in order $(3,5-11)$. Nevertheless, despite such enormous potential, the number of applications that has reached the industrial scale is comparatively rather limited.

From the pioneer commercial large-scale cultures of microalgae in the 1960s in Japan using Chlorella (12), only a few more species have been employed industrially ever since, which include Spirulina sp. and Scenedesmus sp. for healthy food and phycocyanin synthesis (a blue colorant in food and cosmetics), Haematococcus pluvialis for production of astaxanthin (a food colorant), and Dunaliella salina for the manufacture of $\beta$-carotene (a vitamin A substitute and food colorant). In addition, Crypthecodinium cohnii and Schizochytrium sp. are also commercially used for production of polyunsaturated fatty acids (e.g., docosahexaenoic acid), although following a fermentative process (13).

Open ponds were the ancient configurations proposed for microalga production and are still the most widely applied in industrial processes. They usually consist of either circular ponds with a rotating arm to mix the culture, or long channels in a single or multiple loop configuration stirred by paddle wheels (3), although simpler configurations also exist. The main constraints related to operation of these open systems are the impossibility to control contamination, the difficulty to keep the culture environment constant and the cost of the harvesting stage. In order to avoid microbial contamination, highly selective conditions are necessary, so as to guarantee dominance by the selected strain (e.g., D. salina dominance requires highly salted media, whereas Spirulina platensis demands high $\mathrm{pH}$ values); unfortunately, both of these conditions are not suitable for most microalgal species. The direct effect of weather conditions on the characteristics of the open-pond cultivation media also makes it very difficult to keep preset values for the environmental parameters. Regarding the harvesting phase, the huge volume of culture to be harvested (because of the low cell densities attained) magnifies the cost of processing, thus substantially increasing the final cost of the product. Because of the aforementioned serious constraints, open systems have appar- ently reached their upper limit, with little room for further technological improvement.

In view of these difficulties, another approach was envisaged, which is based on the alternative use of closed systems. These are more appropriate for sensitive strains (which grow in nonextreme environments) or when the final product is highly susceptible to microbial degradation (e.g., bacterial metabolization of amino acids and polysaccharides). The closed configuration makes the control of contaminants easier, hence allowing growth in photo-autotrophic, heterotrophic or mixotrophic modes; because of the higher cell mass productivities attained (up to 3-fold those obtained in open systems) (3), harvesting costs per unit mass can also be significantly reduced. Nevertheless, the costs of closed systems are higher than their opensystem counterparts, in addition to several other disadvantages (see Table 2). In fact, despite their higher volumetric productivity, closed systems were not a consensual industrial choice until only recently; intensive capital investments and high production costs account for this realization. In order to minimize production costs, the major factors that play a role in the process ought to be identified and their specific contributions comprehensively studied, in order to maximize advantages and minimize disadvantages. The choice of which configuration is preferable depends obviously on the objective function considered; e.g., wastewater treatment would preclude closed systems, owing to the unacceptably high costs that arise from the large volumes to be processed and the low added value of the feedstock handled.

When improvement in efficacy of a closed photo-bioreactor is the goal, light and $\mathrm{CO}_{2}$ supply are key processing parameters, especially owing to the difficulties associated with their control (viz., assurance of stability throughout time and uniformity throughout space); most of the so-called novel bioreactors do in fact attempt to overcome the constraints related to control of said parameters (14). However, the technology that supports supply of adequate amounts of $\mathrm{CO}_{2}$ to microalgal cells is still poorly developed, which contrasts with the substantial research efforts currently underway on the genetic improvement of native freshwater and marine species for specific applications. On the other hand, although the problem of light supply has sometimes been circumvented by growing the microalgae heterotrophically, not all microalgae (or microalgal products, for that matter) can be produced in this way.

Therefore, issues such as contamination control, gaseous exchanges, mixing patterns, suitability of light supply (which comprises light quality and quantity), geometrical configuration and building material are considered relevant, and will accordingly be discussed to some extent in this review. The aspects of nutrient supply, as well as $\mathrm{pH}$ and temperature control, will not be considered here, because no major improvements are 
Table 2. Main Design Features of Open and Closed Photobioreactors

\begin{tabular}{lll}
\hline \multicolumn{1}{c}{ feature } & \multicolumn{1}{c}{ open systems } & \multicolumn{1}{c}{ closed systems } \\
\hline area-to-volume ratio & large $(4-10$ times higher than closed counterpart) & small \\
algal species & restricted & flexible \\
main criteria for species selection & growth competition & high \\
population density & low & high \\
harvesting efficiency & low & extended \\
cultivation period & limited & unlikely \\
contamination & possible & prevented \\
water loss through evaporation & possible & fair/excellent ${ }^{a}$ \\
light utilization efficiency & poor/fair & fair/high \\
gas transfer & poor & excellent \\
temperature control & none & oxygen control, temperature control \\
most costly parameters & mixing & high \\
capital investment & small &
\end{tabular}

expected therefrom, as their control is rather simple. There has been indeed substantial research on those topics, and the solutions available to date already address conveniently the intended purposes (15). Despite its relative importance, the harvesting phase is also out of the scope of this review.

\section{Reactor Design}

The main parameter that affects reactor design is provision for light penetration, which implies a high surface-to-volume ratio; such penetration is crucial if one wants to improve the photosynthetic efficiency, which is in turn a sine qua non condition to reach high product and biomass productivities. In order to achieve said high surface-to-volume ratio, several shapes have been developed that met with success. These shapes can be grouped in three basic types, viz., tubular, flat plate and fermenter-type; the former two are specifically designed for efficient harvest of sunlight, whereas the latter requires artificial illumination.

Tubular and flat plate reactors are undoubtedly the most popular choices (12), considering that the light source required is free and readily available. Those reactor types are based on the same principle, viz., to guarantee the highest possible areato-volume ratio while ensuring reasonable working volume, mixing pattern and carbon dioxide level. Both reactor configurations may work with a separate unit for gas transfer, and several layouts have been already tested with success (16-20). Such systems comprise: a light-harvesting unit, which employs small diameter tubing so as to provide a high area-to-volume ratio that favors high photosynthetic activity, and a gas exchange unit, in which $\mathrm{CO}_{2}$ is supplied and biomass harvesting is processed. The culture is circulated between those two units by a pump, which needs to be carefully designed and operated in order to prevent shear forces from disrupting cell integrity $(17,21-27)$. Several reactor designs and corresponding productivities are tabulated in Table 3 .

2.1. Tubular Reactors. Most configurations of tubular reactors (TR) are one of the following three types: (i) simple airlift and bubble column, which is composed of vertical tubing (in the form of a vertical tubular reactor) that is transparent so as to allow for light penetration and where $\mathrm{CO}_{2}$ is supplied via bubbling; (ii) horizontal tubular reactor, which is composed of horizontal transparent tubing, usually bearing gas transfer systems attached to the connections; and (iii) helical tubular reactor, which is composed of a flexible plastic tube coiled in a circular framework. Another such reactor that deserves particular attention is the $\alpha$-shape tubular reactor, initially conceived by Lee (28), because of its unique engineering design that is characterized by a unidirectional, high liquid flow rate, concomitant with a low air flow and an excellent angle relative to sunlight.
2.1.1. Vertical Tubular Reactors. The airlift and bubble column reactors are examples of vertical tubular reactors (VTR), regularly composed of polyethylene or glass tubes (Figure 1), which are sufficiently transparent to allow good light penetration but are manufactured with sufficiently common materials so as to be nonexpensive. Air is bubbled at the bottom-a strategy that provides good overall mixing, sufficient supply of $\mathrm{CO}_{2}$, and efficient removal of $\mathrm{O}_{2}$. Polyethylene bags have frequently been used, with advantage taken from their particularly low cost, high transparency and good sterility at startup-due to the high temperatures used during film extrusion $(29,30) ; 32 \mathrm{~cm} \times 250$ cm (ca. $25 \mathrm{~L}$ ) bag reactors were employed by Cohen (31) for cultivation of Porphyridium sp., which were able to reach cell concentrations 3 -fold those typically attained in open ponds. Trotta (30) described a reactor composed of several $30 \mathrm{~cm} \times$ $180 \mathrm{~cm}$ (ca. $50 \mathrm{~L}$ ) polyethylene bag reactors, with various closing devices, and complemented with air and medium supplies. Martinéz-Jerónimo (32) also reported cultivation in $16.8 \mathrm{~cm} \times 224 \mathrm{~cm}$ (ca. $40 \mathrm{~L}$ ) bags to be practical, and to exhibit an improved area-to-volume ratio. Tredici and Rodolfi (33) improved this idea by using a culture chamber made of flexible transparent plastic film contained in a rigid metal framework, so as to form a vertical panel of reduced width. More recently, Chae (34) reported a pilot-scale photo-bioreactor that uses sunlight and flue gas, and consists of a vertical tubular part (kept in the dark) and a horizontal tubular part (subject to sunlight).

Although cultivation of microalgae in the above systems is simple and hence widely employed (including in hatcheries), the corresponding technology is somehow primitive, with obvious constraints derived from the high fragility and the low versatility of the material in stake (21). Furthermore, scale-up of these systems was initially thought to be easy, but accumulated experience (32) has indicated that increases in culture volume decrease bag productivity.

Rigid VTR have also been frequently used. A $33.7 \mathrm{~cm} \times$ $250 \mathrm{~cm}$ (ca. $40 \mathrm{~L}$ ) polyethylene reactor was discussed by Laing (29), in which temperature was controlled by a refrigeration fluid flown through its double wall and in which artificial light was provided from the inside. Myamoto (35), James (36) and Fukami (37) presented similar reactor configurations, but using direct sunlight; their main advantages were low cost and ease of operation. Unfortunately, scale-up is not straightforward; furthermore, in order to provide enough culture volume, as well as efficient gas transfer rate, the reactor diameter should be relatively high when compared to flat plate or tubular loop reactors, a requirement that in turn decreases the area-to-volume ratio and consequently constrains photosynthetic efficiency. Another major drawback is the large angle relative to the direction of sunlight, which causes a high fraction of incident 
Table 3. Main Design Features of Closed Photobioreactors

\begin{tabular}{|c|c|c|c|c|c|c|}
\hline reactor type & $\begin{array}{l}\text { light harvesting } \\
\text { efficiency }\end{array}$ & $\begin{array}{l}\text { degree of } \\
\text { control }\end{array}$ & $\begin{array}{l}\text { land area } \\
\text { required }\end{array}$ & scale-up & productivity $\left(\mathrm{g} \mathrm{L}^{-1} \mathrm{~d}^{-1}\right)$; species & ref \\
\hline vertical tubular & medium & medium & medium & possible & $0.5 ;$ P. cruentum & 27 \\
\hline horizontal tubular & good & medium & poor & possible & $\begin{array}{l}0.25 ; \text { S. platensis } \\
0.7 ; \text { Nannochloropsis sp. }\end{array}$ & $26 ; 30$ \\
\hline helical & medium & good & excellent & easy & $0.4 ;$ S. platensis & 14 \\
\hline$\alpha$-shaped & excellent & good & poor & very difficult & & 18 \\
\hline flat-plate & excellent & medium & good & possible & $\begin{array}{l}0.85 ; \text { Nannochloropsis sp. } \\
2.15 ; \text { S. platensis }\end{array}$ & $46 ; 51$ \\
\hline fermenter type & poor & excellent & excellent & difficult & $0.03-0.05 ;$ several & 48 \\
\hline
\end{tabular}

energy to be reflected back and thus lost in terms of biomass growth purposes (38).

2.1.2. Horizontal Tubular Reactors. Horizontal tubular reactors (HTR) have been on the rise; gas transfer takes place in the tube connection or via a dedicated gas-exchange unit, and the angle toward sunlight is particularly adequate for efficient light harvesting. Such systems can handle large working volumes, because they are not susceptible to contamination. On the other hand, they may generate considerable amounts of heat, which may attain temperature amplitudes of $20{ }^{\circ} \mathrm{C}$ within a single day if (costly) temperature control systems are not provided; thus, it will likely pose a problem for regular operation (39-41).

A long tubular reactor, $14 \mathrm{~cm}$ in diameter, placed horizontally and made of Plexiglas, was reported by Torzillo (40); said device included a diaphragm pump designed to drive the culture to a feeding tank, and gas transfer was allowed in the tube connections. The maximum working volume was $8000 \mathrm{~L}$ in a land area of $80 \mathrm{~m}^{2}$. However, when the area-to-volume ratio was set to that prevailing in open ponds, the photosynthetic efficiency did not improve consistently: the maximum productivity attained was ca. $0.25 \mathrm{~g} \mathrm{~L}^{-1} \mathrm{~d}^{-1}$ when using S. platensis. The major problem encountered was indeed the control of temperature; three different methods were therefore tested, viz., shading the tubes with dark plastic, overlapping the tubes and waterspraying the surface of the tubes. The latter was shown to be efficient, although assurance of low temperatures required a large consumption of water. A thermo-tolerant strain of Spirulina

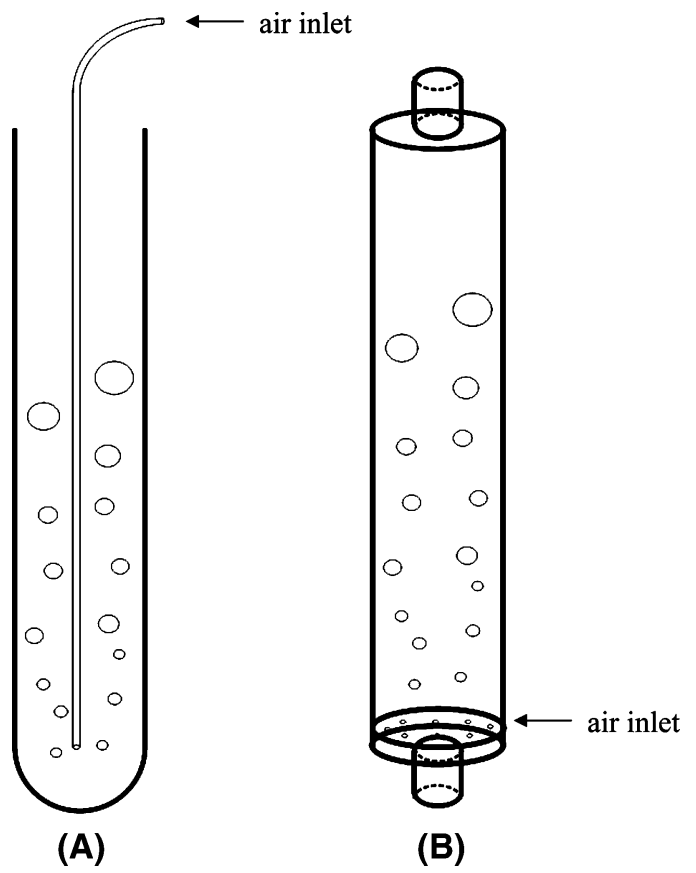

Figure 1. Schematic representation of airlift (A) and bubble column (B) reactors. sp. (able to grow at $46{ }^{\circ} \mathrm{C}$ ) was then used, and the maximum temperature could be kept at $44{ }^{\circ} \mathrm{C}$. A few companies have adopted similar procedures for their industrial operation. For example, the Aquasearch (currently MERA Pharmaceuticals) growth module (42), which is essentially a long HTR for cultivation of $H$. pluvialis (a species tolerant to temperature changes), was cooled down by water spraying whenever necessary.

Gudin and Chaumont (43) have been developing tubular reactor configurations since 1984. They reported a reactor system bearing a capacity of $7000 \mathrm{~L}$ in all, for which a productivity of $36 \mathrm{~g} \mathrm{~m}^{-2} \mathrm{~d}^{-1}$ was claimed when using Phorphyridium cruentum (44). This apparatus was made of several 70-L glass VTR, all connected to a gas exchange unit, and the culture was mechanically pumped between the light harvesting and the gas exchange units-whereas the temperature was controlled by submerging the culture in a water pool as deemed necessary. A major limitation of this reactor was its relatively high cost, coupled with the intrinsic fragility of its constitutive glass.

Richmond (17) and Grima (45) reported similar layouts of HTR, which led to productivities as high as $1.5 \mathrm{~g} \mathrm{~L}^{-1} \mathrm{~d}^{-1}$ with S. platensis and $0.32 \mathrm{~g} \mathrm{~L}^{-1} \mathrm{~d}^{-1}$ with Isochrysis galbana. These systems were based on an external unit designed for light harvesting, connected to a gas exchange tower (placed on top) via an airlift pump (see Figure $2 \mathrm{~A}$ and $\mathrm{B}$, respectively); the working pressure was set so as to provide a low shear stress and a good rate of homogenization, with typical linear velocities of ca. 50 and $30 \mathrm{~cm} \mathrm{~s}^{-1}$, respectively. The main difference between those two configurations pertains to the light harvesting unit: Grima (45) presented a $2.6 \mathrm{~cm} \times 80.8 \mathrm{~m}$ Plexiglas loop submerged in a thermostatic pool, whereas Richmond (17) described parallel sets of $3.0 \mathrm{~cm} \times 20 \mathrm{~m}$ polycarbonate transparent tubes connected by a manifold, with temperature controlled by water spraying. Both of these systems were found rather efficient and cost-effective. Richmond (17) claimed that the best way to increase the working volume is to add more tube sets, in order to maintain an adequate linear velocity and avoid oxygen buildup. Therefore, scale-up in this case poses in principle no problems, because the same tower exchange unit can be duly connected to several extra sets of tubes. The major drawback is the land area occupied; in fact, the tubes in the light-harvesting unit are very narrow, so industrial volumes (i.e., 5 000-10000 L) can be reached only at the expense of a paramount number of tubes, which are supposed to be placed horizontally. Therefore, economic feasibility should be assessed in advance; otherwise this type of apparatus may not be costeffective at all, as discussed elsewhere (46).

Another advance in microalgal cultivation systems is the nearhorizontal tubular reactor (NHTR) designed by Tredici (47) (see Figure 3), which consists of sets of parallel tubes made of flexible plastic (typically $6.4 \mathrm{~m}$ in length, $43 \mathrm{~mm}$ diameter and $0.15 \mathrm{~mm}$ thick), connected by PVC manifolds. The upper manifolds are used as degassers, and a perforated pipe inserted 


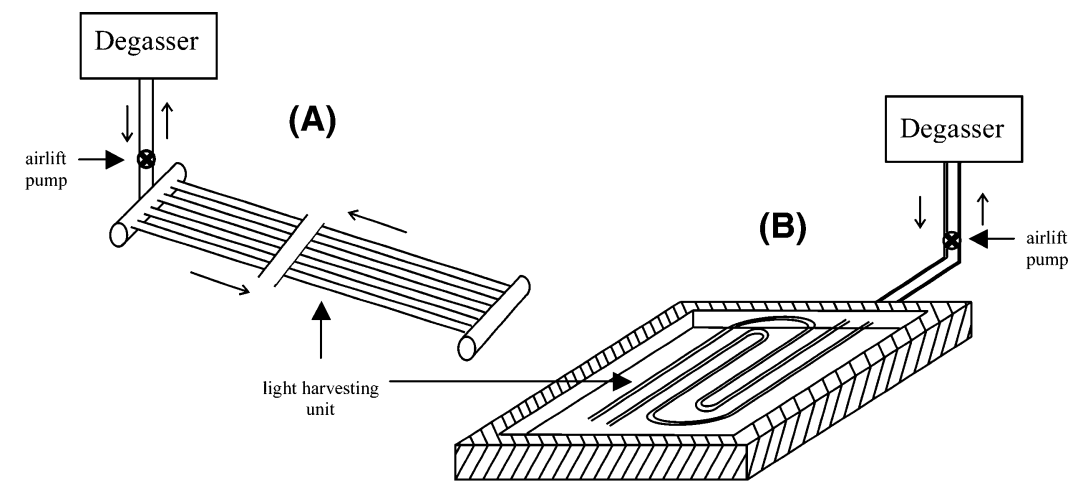

Figure 2. Schematic representation of horizontal tubular reactor with a degassing unit and a light harvesting unit, composed of parallel sets of tubes (A) or a loop tube (B).
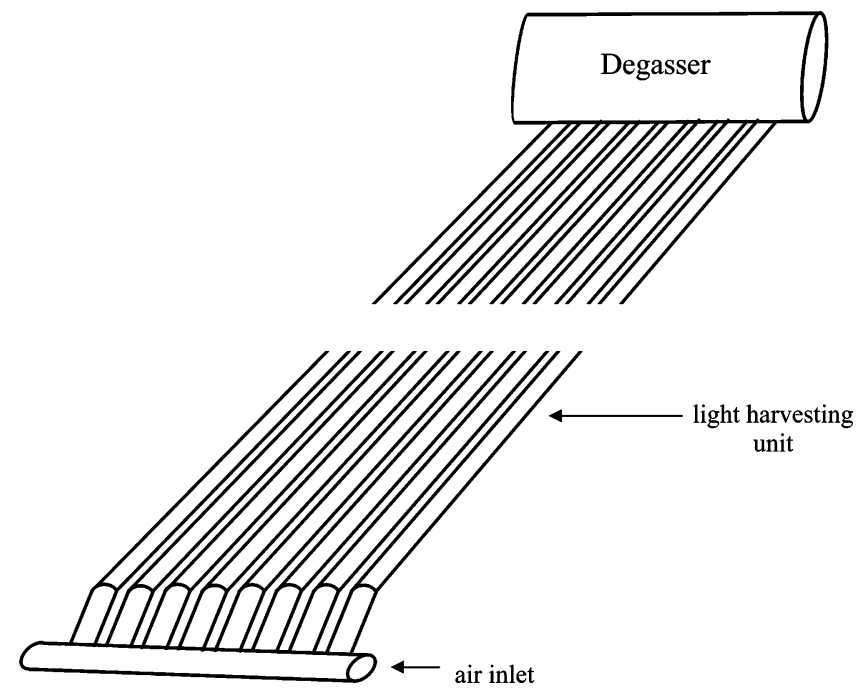

Figure 3. Schematic representation of near horizontal tubular reactor.

in the lower manifolds is used to inject air in each individual tube. The tubes are placed at an angle of $5-7^{\circ}$ relative to the horizontal plan. Temperature is controlled by activating water spraying onto the reactor when the culture temperature exceeds a preset value. The maximum volume tested, $4000 \mathrm{~L}$, obtained with a set of 8 parallel tubes $44 \mathrm{~m}$ in length, was associated with a mean productivity of $0.7 \mathrm{~g} \mathrm{~L}^{-1} \mathrm{~d}^{-1}$ in the case of Nannochloropsis sp. The main advantage of this system is the high area-to-volume ratio and its easy scale-up, coupled with the possibility for a higher degree of control (41). Surprisingly, the temperature control was not efficient, and a day-night temperature gap of ca. $14{ }^{\circ} \mathrm{C}$ during summer and of ca. $22{ }^{\circ} \mathrm{C}$ during spring was actually recorded. Such a poor control led to different biochemical compositions of the microalga throughout the year. However, the major drawback of this system was probably its low gas transfer rate, arising from a large length and a small diameter (48).

2.1.3. Helical Tubular Reactors. Helical tubular reactors (HeTR) are a suitable alternative to straight TR. The most frequently used layout is the Biocoil, initially proposed by Robinson (49) and currently traded by Biotechna (Melbourne, Australia). This reactor is composed of a set of polyethylene tubes $(3.0 \mathrm{~cm}$ of inner diameter) coiled in an open circular framework, coupled with a gas exchange tower and a heat exchange system; a centrifugal pump drives the culture broth through the long tube to the gas exchange tower (see Figure 4A). A few authors $(12,18,20,21,50)$ experimented with and eventually improved such a design, so it ranks at present among the most effective ones as a result of its high area-to-volume ratio on the one hand, and the requirement of only a small land area for relatively large volumes on the other. Placing a light source inside the coil and then providing a reasonable control of light intensity may compensate for the large angle toward sunlight. Scale-up of this type of system is easy; one has simply to increase the number of parallel layers of tubes in the coil, thus maintaining the hydraulic head essentially unchanged (21). However, use of a centrifugal pump to drive the culture to the upper side of the tubing might increase shear stress, which then would become a limiting step for biomass productivity. Therefore, not all algal species are suitable for culture in this system; the recirculation pump may damage some, whereas others may be engaged in fouling on the inside of the reactor tubing (12). The system described by Travesio (20) operates with an airlift column instead of a centrifugal pump, and may be useful toward reduction of shear stress and consequent minimization of cell damage.

Morita (51) proposed a conical helical reactor that encompasses a light-harvesting unit composed of PVC tubing $(0.16$ $\mathrm{m}$ of internal diameter) coiled in a conical framework (see Figure 4B), a degassing unit placed above and a heat exchanger. An air pump is used to force the culture from the heat exchanger, in an ascending trajectory, to the light-harvesting unit, which is in turn connected to the degasser, placed at the same level; the culture is then returned to the heat exchanger unit in a descending trajectory. The same degasser and heat exchanger can be connected to several light-harvesting units, as also tested by the same author. The main advantage of this system its the high efficiency in light harvesting; the conical shape distributes the radiant energy input to a larger photo-receiving area, i.e., it improves spatial distribution of light. The heat exchanger has proven efficient in maintaining temperature within a narrow interval $\left(28 \pm 3{ }^{\circ} \mathrm{C}\right)$. One major disadvantage is that, unlike the Biocoil, this arrangement cannot be easily scaled-up. In fact, although the conical light receptor is very efficient, the angle and height are strictly defined, so the only way to maintain high photosynthetic rates is to increase the number of light harvesting units, which also leads to larger energy losses in the complicated branches of the flow networks (52); hence the land area productivity will be significantly reduced.

2.1.4. $\alpha$-Shaped Reactors. Lee (28) described a 300-L $\alpha$-shaped tubular reactor, with sets of $2.5 \mathrm{~cm} \times 25 \mathrm{~m}$ transparent tubes made of PVC; it used an airlift pump to promote an ascending/descending trajectory, with several $\mathrm{CO}_{2}$ injection points along its path (see Figure 5). This configuration presents several advantages from the engineering point of view. For example, the fluid is pumped in a single direction (except in the airlift tubes), so a high flow rate is possible at the expense of relatively low air supply rates in the rising tubes. The 


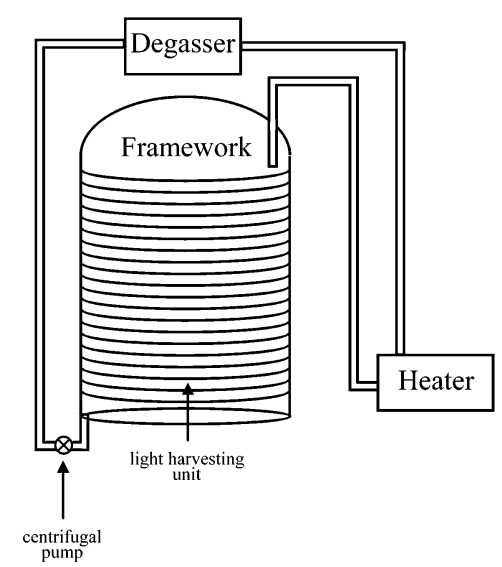

(A)

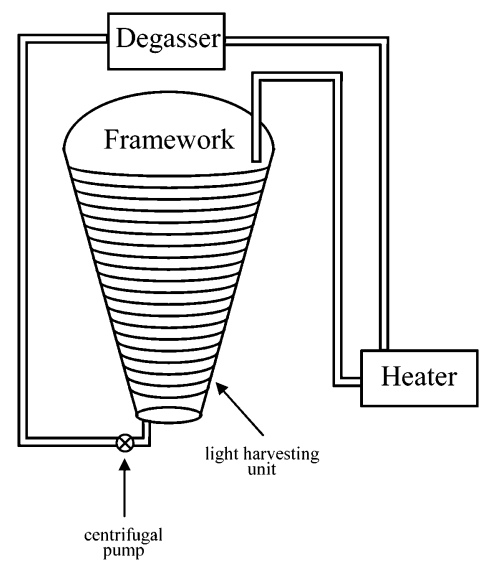

(B)

Figure 4. Schematic representation of helical tubular reactors: Biocoil (A) and conical framework (B).

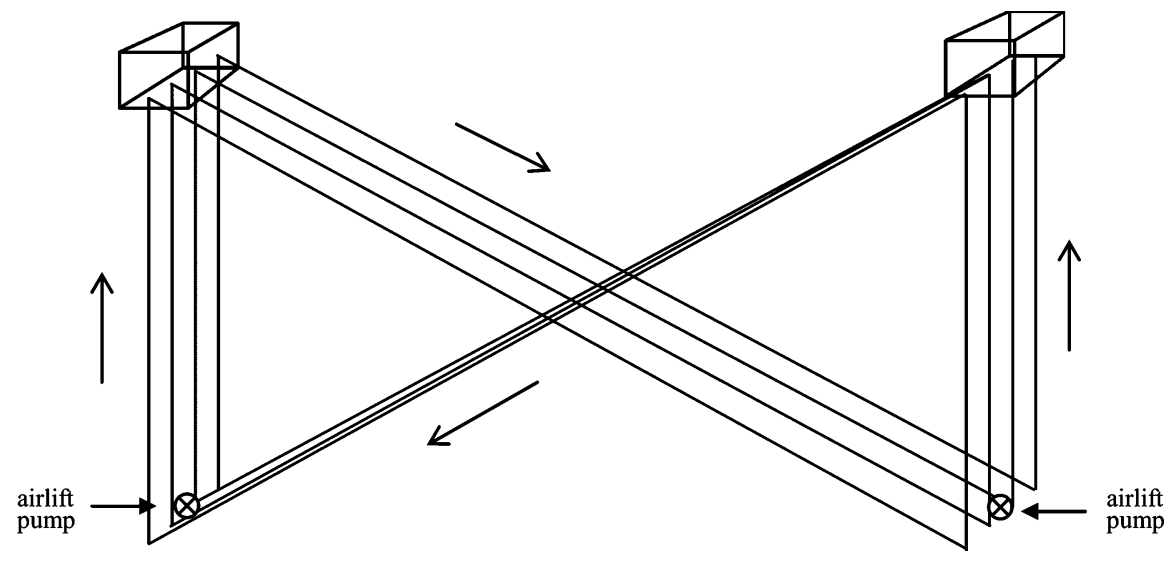

Figure 5. Schematic representation of $\alpha$-shaped reactor.

ascending and descending trajectories are placed at a $45^{\circ}$ angle toward sunlight, so light harvesting is rather efficient.

2.2. Flat Plate Reactors. Flat plate reactors (FPR) are conceptually designed to make efficient use of sunlight; hence, narrow panels are usually built so as to attain high area-tovolume ratios (see Figure 6A). In the early 1980s, FPR were considered expensive and were even claimed to exhibit deficiencies in culture flow control (53). A 500-L FPR was developed by Pulz (16), in which the culture was circulated from an open gas exchange unit through several parallel panels placed horizontally. The culture flew at a high linear speed (viz., $1.2 \mathrm{~m}$ $\mathrm{s}^{-1}$ ), but hydrodynamic parameters usually lay in a safe operating range for the sake of cell integrity. The greatest advantage of this system is its provision of an open gas transfer unit, which has proven efficient in overcoming the problem of oxygen buildup; however, such an open zone restricts effectiveness of contamination control, as compared with completely closed reactors. Richmond (54) presented a similar system, composed of several 200-L units potted together, each unit being composed of $200 \mathrm{~cm} \times 100 \mathrm{~cm} \times 10 \mathrm{~cm}$ glass plates. The main difference was the absence of a gas transfer unit and instead bubbling of compressed air at the bottom, through a perforated plastic tube. A closed system of water spraying was employed to control temperature; the sprayed water was then collected in troughs and recirculated through a ventilated water column for refrigeration. One such reactor, with an overall volume of $1000 \mathrm{~L}$, was tested with various light paths for cultivation of Nannochloropsis sp.; the maximum volumetric productivity, $0.85 \mathrm{~g} \mathrm{~L}^{-1} \mathrm{~d}^{-1}$, was attained with the minimum light path, i.e., $1.3 \mathrm{~cm}$.

A different FPR was reported by Iqbal (55), who described a V-shaped apparatus characterized by unusually interesting engineering features, viz., very high mixing rate and very low shear stress (see Figure 6B); scale-up of its reduced capacity (2 L) is, however, still to be done.

Introduction of alveolar panels (see Figure 6C), made of PVC, polycarbonate or polymethyl methacrylate, for microalga cultivation has meanwhile emerged as a successful concept, because of their high versatility and commercial availability. Several systems using that type of panels have been built and duly tested. Tredici (56-59) used double-row sets of alveolar plates placed horizontally, where culture was circulated in the upper row and thermostated water was circulated in the lower row. Tredici (59) also described a bubble column FPR, in which alveolar plates were mounted vertically, and the culture was mixed and degassed simply by air bubbling at the bottom of each channel. Its productivity was very high using $S$. platensis $\left(2.15 \mathrm{~g} \mathrm{~L}^{-1}\right.$ $\mathrm{d}^{-1}$ ), when compared with that obtained in open ponds under similar conditions $\left(0.15 \mathrm{~g} \mathrm{~L}^{-1} \mathrm{~d}^{-1}\right)$.

In general, the main advantages of FPR are their high productivity and uniform distribution of light and, in the specific case of bubbled column FPR, the absence of a driving pump. Furthermore, these reactors can be oriented toward the sun, hence permitting a better efficiency in terms of energy absorbed from incident sunlight. Pusparaja (60) discussed a reactor 


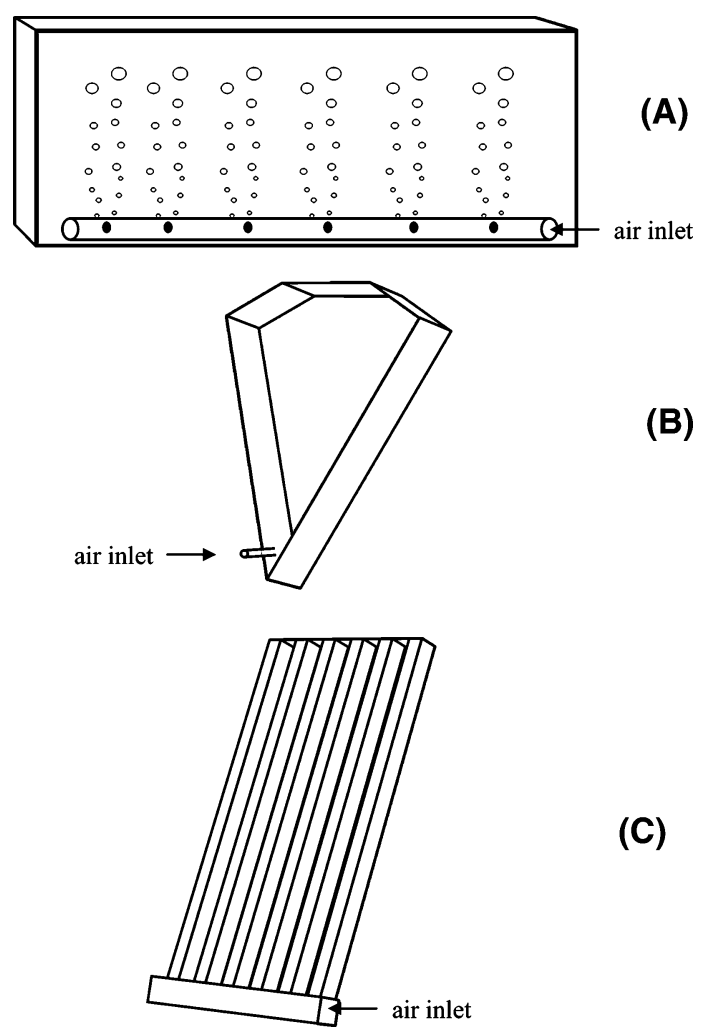

Figure 6. Schematic representation of flat panel reactors: flat panel bubbled in the bottom (A), V-shaped panel (B) and alveolar panel (C).

encompassing an alveolar panel system oriented toward the sun, coupled with an open raceway for gas transfer. The use of such alveolar panels as solar receptors increased volumetric productivity from $0.18 \mathrm{~g} \mathrm{~L}^{-1} \mathrm{~d}^{-1}$ in open ponds to $0.31 \mathrm{~g} \mathrm{~L}^{-1} \mathrm{~d}^{-1}$. Although the volumetric productivity attained inside the panels is higher, open raceways are the most often used cultivation systems for microalgae, so said combination may be of great practical significance. The main disadvantage of alveolar panels is oxygen buildup, which arises from the high photosynthetic activity reached, coupled with the small diameter of the reactors used $(57,59)$.

2.3. Fermenter-Type Reactors. The least expanded systems for microalga cultivation are conventional fermenter-type reactors (FTR) (see Figure 7). These apparata present indeed an intrinsic disadvantage: the area-to-volume ratio is quite low, so sunlight harvesting efficiency is poor. To overcome this nuclear drawback, sophisticated systems of internal illumination were developed, which are able to provide a more homogeneous distribution of light. When possible, microalgae may be heterotrophically cultivated in FTR, using appropriate organic carbon sources. A 250-L FTR was built by Pohl (61) with stainless steel and illuminated internally by fluorescent lamps placed inside narrow glass (or Plexiglas) tubes; $\mathrm{CO}_{2}$-enriched air was bubbled at the bottom, through a V-shaped (i.e., low shear stress) stirrer. Such a system was operated batch-, semicontinuous- and continuous-wise. The operation parameters could be fully controlled, so axenic cultures were maintained for long periods, as considered crucial for production of certain high-value metabolites. Although biomass productivity was quite low (typically $30-50 \mathrm{mg} \mathrm{L}^{-1} \mathrm{~d}^{-1}$ ), there is still plenty of room for enhancement of growth parameters with this reactor configuration.

Ogobona (62) has also developed an FTR using both sun and artificial light, which may be a leap forward in terms of reduction of operating costs.

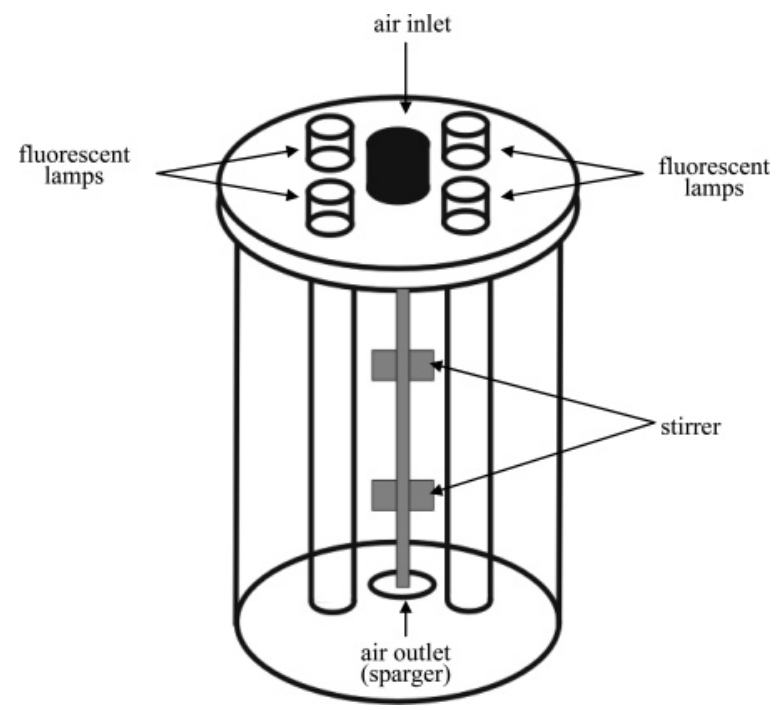

Figure 7. Schematic representation of fermenter-type bioreactor.

Several laboratory-scale FTR have been developed (63-68), but there is scarce information available on their large-scale counterparts. The main advantage of these systems is of course the accurate control of processing parameters, including light, coupled with the vast experience accumulated in food and pharmaceutical industries in terms of the scale-up thereof. Therefore, should productivity be enhanced, FTR would certainly become a competitive alternative for industrial manufacture of biochemical products brought about by microalgae.

\section{Processing Parameters}

Effective supply of light and carbon dioxide to the whole cell culture, as well as other physical and nutritional requirements, demands uniform dispersion of microalgae in a nonlimiting nutrient culture medium. Since adequate mixing levels in many reactor configurations are often obtained via injection of gas into the system, mixing and gas transfer are thus closely related to each other.

\subsection{Gaseous Transfer}

3.1.1. Carbon Source. Because nearly $50 \%$ of the whole microalgal biomass is made up of carbon (69), this element is a major nutrient for cell growth. When grown photo-litotrophycally, all microalgae use inorganic carbon sources to synthesize organic compounds (70). In aqueous environments, inorganic carbon may exist in several alternative chemical forms, $\mathrm{CO}_{2}(\mathrm{aq}), \mathrm{H}_{2} \mathrm{CO}_{3}, \mathrm{HCO}_{3}{ }^{-}$and $\mathrm{CO}_{3}{ }^{2-}(71)$, which are interconvertible via reactions controlled by temperature and $\mathrm{pH}(69)$. The possibility that microalgae use carbon in $\mathrm{CO}_{2}$ form only or that they also take up the $\mathrm{HCO}_{3}{ }^{-}$and $\mathrm{CO}_{3}{ }^{2-}$ forms is not a critical issue, because reactions that interconvert $\mathrm{CO}_{2}, \mathrm{H}_{2} \mathrm{CO}_{3}$, $\mathrm{HCO}_{3}{ }^{-}$and $\mathrm{CO}_{3}{ }^{2-}$ in soluble form are sufficiently fast not to be limiting steps in $\mathrm{CO}_{2}$ demand by cells $(14,71)$. Besides, e.g., for Chlorella vulgaris, inorganic carbon affinity at the cell surface was found to be very low (not above $1 \mu \mathrm{g}$ carbon/L) (71), and synthesis of carbonic anhydrase (which catalyzes the aforementioned inorganic carbon interconversion) is enhanced when cells are exposed to a low- $\mathrm{CO}_{2}$ environment.

Detailed studies on the influence of the carbon source upon microalga productivity (71) have indicated that, although $\mathrm{HCO}_{3}{ }^{-}$ is easily absorbed by cells, it is a poor source of carbon when compared with $\mathrm{CO}_{2}$. In fact, it is possible to achieve a linear response in microalgal carbon biomass with mass input of 
Table 4. Values for $K_{\mathrm{L}}$ and $K_{\mathrm{L}} a$ Using Several Gas Transfer Methods

\begin{tabular}{cllll}
\hline transfer method $^{a}$ & \multicolumn{1}{c}{$K_{\mathrm{L}} a\left(\mathrm{~min}^{-1}\right)$} & \multicolumn{1}{c}{$A\left(\mathrm{~m}^{2}\right)$} & $a\left(\mathrm{~m}^{-1}\right)$ & $K_{\mathrm{L}}(\mathrm{m} / \mathrm{s})$ \\
\hline HIFO & $1.48 \times 10^{-2}$ & 1.7 & 1700 & $1.45 \times 10^{-7}$ \\
HIFI & $1.33 \times 10^{-2}$ & $1.4 \times 10^{-1}$ & 140 & $1.59 \times 10^{-6}$ \\
HIFO & $(3.6-7.5) \times 10^{-3}$ & $2.38 \times 10^{-3}$ & 4.76 & $(1.26-2.64) \times 10^{-5}$ \\
bubbling & $7.00 \times 10^{-3}$ & $1.1 \times 10^{-3}$ & 1.05 & $1.11 \times 10^{-4}$ \\
bubbling & $(7.59-21.7) \times 10^{-2}$ & $\mathrm{na}^{b}$ & $2.15-6.21$ & $(5.83-5.88) \times 10^{-4}$ \\
bubbling & $(9-94) \times 10^{-2}$ & $\mathrm{na}^{b}$ & $42.8-147.2$ & $(3.51-10.6) \times 10^{-5}$
\end{tabular}

${ }^{a}$ HIFO, hollow hydrophobic fiber membrane; HIFI, hollow hydrophilic fiber membrane. ${ }^{b}$ Not available.

carbon (which corresponds to an efficiency of virtually 100\%) only if limited inputs of inorganic carbon and narrow $\mathrm{pH}$ ranges are permitted; e.g., Phaeodactylum tricornutum produced up to $25 \mathrm{mg} \mathrm{d}^{-1}$ of algal carbon when $\mathrm{pH}$ of the culture was below 9.0 (71). Beyond a given threshold, $\mathrm{pH}$ control becomes difficult, so chemical precipitation of salts containing $\mathrm{CO}_{3}{ }^{2-}, \mathrm{OH}^{-}$and $\mathrm{PO}_{4}{ }^{3-}$ will likely occur, hence leading to chemical deterioration of the medium and possible cell injury. The upper threshold of productivity is therefore considerably lower than that resulting from light limitation, and about $1 / 10$ that obtained by replacing $\mathrm{HCO}_{3}{ }^{-}$by $\mathrm{CO}_{2}$. A general consensus exists about preference of microalgae for $\mathrm{CO}_{2}$ (as inorganic carbon source), as it is easily controlled and produces minor $\mathrm{pH}$ changes. Note that $\mathrm{CO}_{2}$ in the open air accounts for only ca. $0.03 \%$ (v/v) (69), so fluxes of carbon transfer to the culture are small, even in the presence of extended interface areas or enhanced mixing. Consequently, $\mathrm{CO}_{2}$-enriched air is the most commonly employed nutrient gas mixture, so as to force light to become the sole limiting factor.

3.1.2. Transport Process. When $\mathrm{CO}_{2}$ is injected at a given point in a culture, a concentration gradient builds up as it is consumed by cells and/or lost to the atmosphere. According to the two-film theory, mass transfer of $\mathrm{CO}_{2}$ from the gas phase to the cell phase occurs through sequential stages: transport from the bulk of the gas to the thin gaseous film at the immediate vicinity of the interface; diffusion through this gas film; transport across the gas/liquid interface; diffusion through the adjacent liquid film; transport from the thin liquid film to the bulk of the liquid; transport from the bulk of the liquid to the thin liquid film at the immediate vicinity of the cell wall; diffusion through the outer cell liquid film; and finally, metabolic uptake by the cell. The overall resistance over the entire path distance can be calculated by adding up the aforementioned single resistances, as they occur in series; however, most of the resistance actually lies on the liquid film. In an efficiently stirred bioreactor, concentration gradients within the bulk liquid are marginal, so (even in the presence of dense microalgal cultures) resistance within the gas bubbles is larger than at the boundary layer of cells (14). Consequently, resistance raised by the liquid film adjacent to the interface essentially limits the rate of $\mathrm{CO}_{2}$ transfer. In fact, comparative studies (14) encompassing overall mass-transfer resistances and gas/liquid mass-transfer resistance revealed their similarity in order of magnitude, thus confirming that $\mathrm{CO}_{2}$ transport is mainly controlled by resistance offered by the liquid film.

The rate of $\mathrm{CO}_{2}$ uptake by cells eventually determines the rate at which it will be transferred to the medium, if steadystate conditions prevail. The rate of mass transfer is, in general, proportional to the driving force for said transfer (expressed in terms of a concentration difference involving one actual bulk concentration of one phase and an equivalent bulk concentration of the other phase) and the area available for transfer. The proportionally coefficient is the sum of the reciprocals of all resistances to transfer and is usually denoted as an overall masstransfer coefficient. In the present case, since liquid-phase mass transfer resistance dominates overall resistance, the rate of mass transfer of $\mathrm{CO}_{2}\left(N_{\mathrm{CO}_{2}}\right)$ is approximately given by

$$
N_{\mathrm{CO}_{2}}=k_{\mathrm{L}} a\left(C_{\mathrm{CO}_{2} \mathrm{~L}} *-C_{\mathrm{CO}_{2} \mathrm{~L}}\right)
$$

where $k_{\mathrm{L}}$ is the liquid-phase mass transfer coefficient, $a$ is the specific area available for mass transfer, $C_{\mathrm{CO}_{2} \mathrm{~L}}$ * is the concentration of $\mathrm{CO}_{2}$ in the culture medium that would equilibrate its actual partial pressure on the gas side, and $C_{\mathrm{CO}_{2} \mathrm{~L}}$ is the concentration of $\mathrm{CO}_{2}$ in the bulk of culture medium.

The lumped parameter $k_{\mathrm{L}} a$ characterizes the $\mathrm{CO}_{2}$ mass transfer capability of the reactor and thus determines whether a certain reactor will be able to sustain a given rate of cell growth. Regarding transfer of $\mathrm{CO}_{2}$, said parameter is of the utmost importance in design, scale-up and operation steps for a biomass culture system (72). Some properties of the bubbles affect mainly $k_{\mathrm{L}}$, whereas others affect mainly $a$. Furthermore, the amount of metabolites present in the medium depends on cell concentration, which will also affect $k_{\mathrm{L}} a$ since, in general, metabolites modify the surface tension of the medium and thus act as an extra barrier to mass transfer (73).

Studies $(73,74)$ have been undertaken to compare $k_{\mathrm{L}} a$ values obtained under bubbling (at different gas and liquid flow rates and at distinct bubble sizes) and under diffusion through hollowfiber membranes (of different areas and distinct construction materials); $k_{\mathrm{L}} a$ typically increases with increasing liquid tangential flow rate, because of thinning of the liquid boundary layer. When comparing the rate of mass transfer obtained under bubbling or by diffusion (with all other operating conditions remaining similar) (75), it was observed that $k_{\mathrm{L}} a$ values were higher in the latter case: an overall volumetric coefficient for $\mathrm{CO}_{2}$ transfer of $1.48 \times 10^{-2} \mathrm{~min}^{-1}$ was found for a hydrophobic membrane, $1.33 \times 10^{-2} \mathrm{~min}^{-1}$ for a hydrophilic membrane and $7.0 \times 10^{-3} \mathrm{~min}^{-1}$ for plain bubbling (see Table 4). Such increasingly lower values are a consequence of the substantially shorter interfacial area available; in fact, the individual volumetric mass transfer coefficient values $\left(k_{\mathrm{L}}\right)$ were higher for bubbling $\left(1.11 \times 10^{-2} \mathrm{~m} \mathrm{~s}^{-1}\right)$ than for diffusion $\left(1.45 \times 10^{-7}\right.$ and $1.59 \times 10^{-6} \mathrm{~m} \mathrm{~s}^{-1}$ for hydrophobic and hydrophilic membranes, respectively), because of the turbulent conditions associated with the former. Therefore, use of microporous hollow fibers instead of plain bubbling offers technological enhancements in effectiveness of mass transfer at the expense of larger $a$. In addition, this type of system offers opportunity to recirculate gas and hence permits lower gas pressures to be used, which in turn reduce operating costs. However, Carvalho and Malcata (75) have demonstrated that overall metabolic enhancement in microalgal growth is essentially nil, probably because $\mathrm{CO}_{2}$ and light-rich periods did not coincide with each other (both in space and time).

Other studies (71) pertaining to continuous cultures limited in carbon afforded interesting relationships between bubble size, gas flow rate and partial pressure of $\mathrm{CO}_{2}$. Optimum biomass productivity was obtained by using either high bubbling rate 


\begin{tabular}{|c|c|c|c|c|c|c|c|c|}
\hline \multirow[b]{2}{*}{ process } & & \multirow[b]{2}{*}{ type of reactor } & \multirow[b]{2}{*}{ alga } & \multirow[b]{2}{*}{ ref } & \multicolumn{4}{|c|}{ feature } \\
\hline & & & & & $\begin{array}{l}\text { gas } \\
\text { transfer }\end{array}$ & mixing & $\begin{array}{l}\text { hydrody- } \\
\text { namic stress }\end{array}$ & scale-up \\
\hline \multicolumn{9}{|c|}{ Passive Mode } \\
\hline $\begin{array}{l}\text { surface } \\
\quad \text { aeration }\end{array}$ & & $\begin{array}{l}\text { unstirred shallow } \\
\text { ponds }\end{array}$ & D. salina & 5 & poor & very poor & very low & difficult \\
\hline $\begin{array}{l}\text { membrane } \\
\text { transfer }\end{array}$ & & $\begin{array}{l}\text { hollow-fiber } \\
\text { membrane }\end{array}$ & Nannochloropsis sp. & 50 & excellent & uniform $^{a}$ & medium & medium \\
\hline \multirow{5}{*}{$\begin{array}{l}\text { gas injection } \\
\text { into culture }\end{array}$} & & & Active Mode & & & & & \\
\hline & at bottom of & air-lift & P. tricornutum & 79 & high & uniform & low & medium \\
\hline & reactor & bubble column ${ }^{b}$ & P. tricornutum & 33 & fair & fair & low & medium \\
\hline & & stirred-tank & filamentous & 48 & low/high & uniform & high & difficult \\
\hline & at given point & $\begin{array}{l}\text { flat-plate } \\
\text { tubular }\end{array}$ & $\begin{array}{l}\text { Spirulina } \\
\text { Spirulina }\end{array}$ & $\begin{array}{l}45 \\
11\end{array}$ & $\begin{array}{l}\text { high } \\
\text { fair/high }\end{array}$ & $\begin{array}{l}\text { uniform } \\
\text { uniform }\end{array}$ & $\begin{array}{l}\text { low/high } \\
\text { low/high }\end{array}$ & $\begin{array}{l}\text { difficult } \\
\text { difficult }\end{array}$ \\
\hline $\begin{array}{l}\text { gas } \\
\text { exchanger }\end{array}$ & & $\begin{array}{l}\text { tubular solar } \\
\text { receptor }\end{array}$ & P. cruentum & 27 & good & $\begin{array}{l}\text { good (by } \\
\text { pumping) }\end{array}$ & medium & difficult \\
\hline
\end{tabular}

${ }^{a}$ Depends on mixing device. ${ }^{b}$ Large bags.

(with small sized bubbles) with low inlet pressure of $\mathrm{CO}_{2}$ or low bubbling rate with high inlet pressure of $\mathrm{CO}_{2}$ (irrespective of bubble size). Although more efficient ( $47 \%$ vs $14 \%$, in terms of assimilation efficiency), the former option could bring about problems of cell flotation and consequent washout. At $1 \%$ (v/ v) $\mathrm{CO}_{2}$, productivity was essentially independent of bubble size, probably because partial pressure in the culture was already high enough; it is indeed possible to achieve light limitation under these conditions. In conclusion, total carbon input flux is determined by both gas bubbling rate and partial pressure of $\mathrm{CO}_{2}$. Selecting the proper combination of these two variables is the key to avoid carbon limitation in intensive culturing.

In terms of biomass produced, the differences in value between the several parameters affecting it make an overall comparison difficult to establish. Concerning production costs, the literature is scarce; hence, reliable economic data are to be generated in the future, before a consistent comparison of performances can be accurately done.

3.1.3. $\mathrm{CO}_{2}$ Transfer Systems. In algal mass culture systems, it is important to obtain a reliable prediction of $\mathrm{CO}_{2}$ transfer rates for accurate design, scale-up and operation. The occurrence of chemical reactions between $\mathrm{CO}_{2}$ and $\mathrm{OH}^{-}, \mathrm{H}_{2} \mathrm{O}$ and $\mathrm{NH}_{3}$ in the liquid phase may lead to enhanced rates of $\mathrm{CO}_{2}$ absorption by the culture medium (72); therefore, the $\mathrm{CO}_{2}$ exchange flux from the gaseous to liquid phase is governed not only by diffusion kinetics, but also (depending on the relative magnitude of the reaction rates observed) by kinetics of the reactions in the liquid film at the vicinity of the interface.

The critical concentration of $\mathrm{CO}_{2}$ necessary for optimal growth of a particular microalga cannot be stated in general, as it strongly depends on the delivery system implemented in the culture vessel. Since transfer of $\mathrm{CO}_{2}$ occurs through the interface between the gaseous mixture and the liquid medium culture, two main processes to increase such an interface area can be devised: (i) passive mode, where extensive gas/culture interface areas are used and gas diffuses into the culture; and (ii) active mode, where use of an extra apparatus for aeration either by injecting the gas into the medium or spraying the medium into the gas forces expansion of the contact area between gas and culture (69) (see Table 5).

Regarding passive mode, large interface areas between the gas and the culture medium can be obtained by: either (i) using large open-air ponds, where gas exchanges occur by surface driven aeration (see Figure 8A), e.g., cultivation of $D$. salina in Australia, in natural lakes of 50-300 ha, or similar cultivation of Chlorella and Spirulina spp. in paddle-wheel (or circular) mixed ponds of ca. 1 ha; or (ii) via membranes, through which gas diffuses into the culture. No examples have been reported pertaining to surface aeration in closed systems, probably owing to the huge areas that would be involved. Conversely, membranemediated transfer has already been tested in closed systems (74-76).

When membrane aeration is considered, gas diffuses through a permeable membrane, which can be either microporous or made of a material possessing high gas permeability (e.g., silicone). The membrane is often arranged as a coil or bank of tubes, placed inside the reactor vessel (77). Alternatively, the bank of tubes may be contained in an appropriate housing, which will work as a gas exchanger, connected to the reactor vessel by plastic tubing (75). One configuration tested with success encompasses diffusion of pure $\mathrm{CO}_{2}$ through permeable silicone tubing, coiled up in order to maximize transfer area in a reduced space (76). This kind of system theoretically offers several advantages when compared with bubbling, viz., exclusion of $\mathrm{CO}_{2}$ losses to atmosphere, possibility to accurately control $\mathrm{CO}_{2}$ transfer rates, and no requirement for air $/ \mathrm{CO}_{2}$ mixing chamber or even highly pure $\mathrm{CO}_{2}$ (as it will not be in close contact with the culture). Better overall efficiencies are expected for this system when compared with bubbling $(13-20 \%)$ or gas exchange (25-65\%) (76). However, such a system suffers from severe drawbacks: (i) since the transfer rate is proportional to the membrane area, long tubing membranes are normally required, which raise the investment costs (21); (ii) especially for highly salted media, high inner pressures are necessary in order to balance transfer rates produced by bubbling, which force the use of thick membrane walls (the only ones that can handle such high pressures); and (iii) pressurization of the membrane often promotes expansion of the material, thus originating microspacing within the polymer network of the membrane, to which bacteria may adhere and eventually grow, hence reducing contact area between membrane and culture, and decreasing transfer rate throughout time.

An alternative possibility relies on the potential of microporous hollow-fiber membranes, i.e., bundles of polymeric porous fibers, potted to inlet/outlet ports in their ends and contained in adequate housings $(74,75)$ (see Figure 8B), which may also function as gas exchangers in the setup or as the whole reactor itself. Commercial fiber modules usually contain tiny hollow fibers, with typical inner diameters of ca. $250 \mu \mathrm{m}$; their permeability obviously depends on the construction material. As a result of the usually large number of fibers inside each module, the ratio between membrane exposed area and external 
(A)

\begin{tabular}{|l|}
\hline air \\
\hline culture \\
\hline
\end{tabular}

(B)

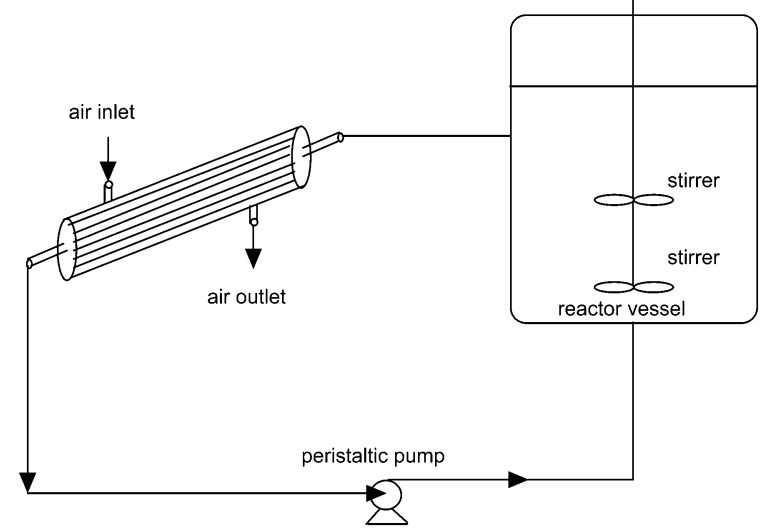

(C)

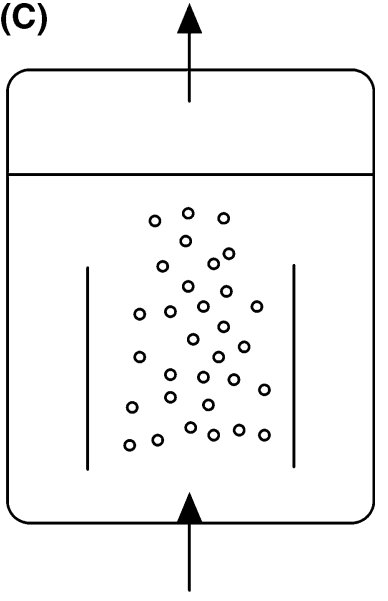

air inlet

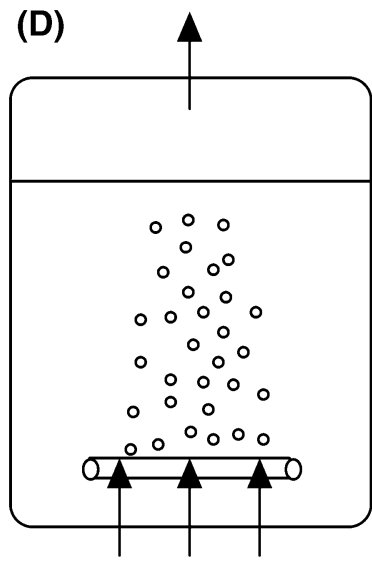

air inlet
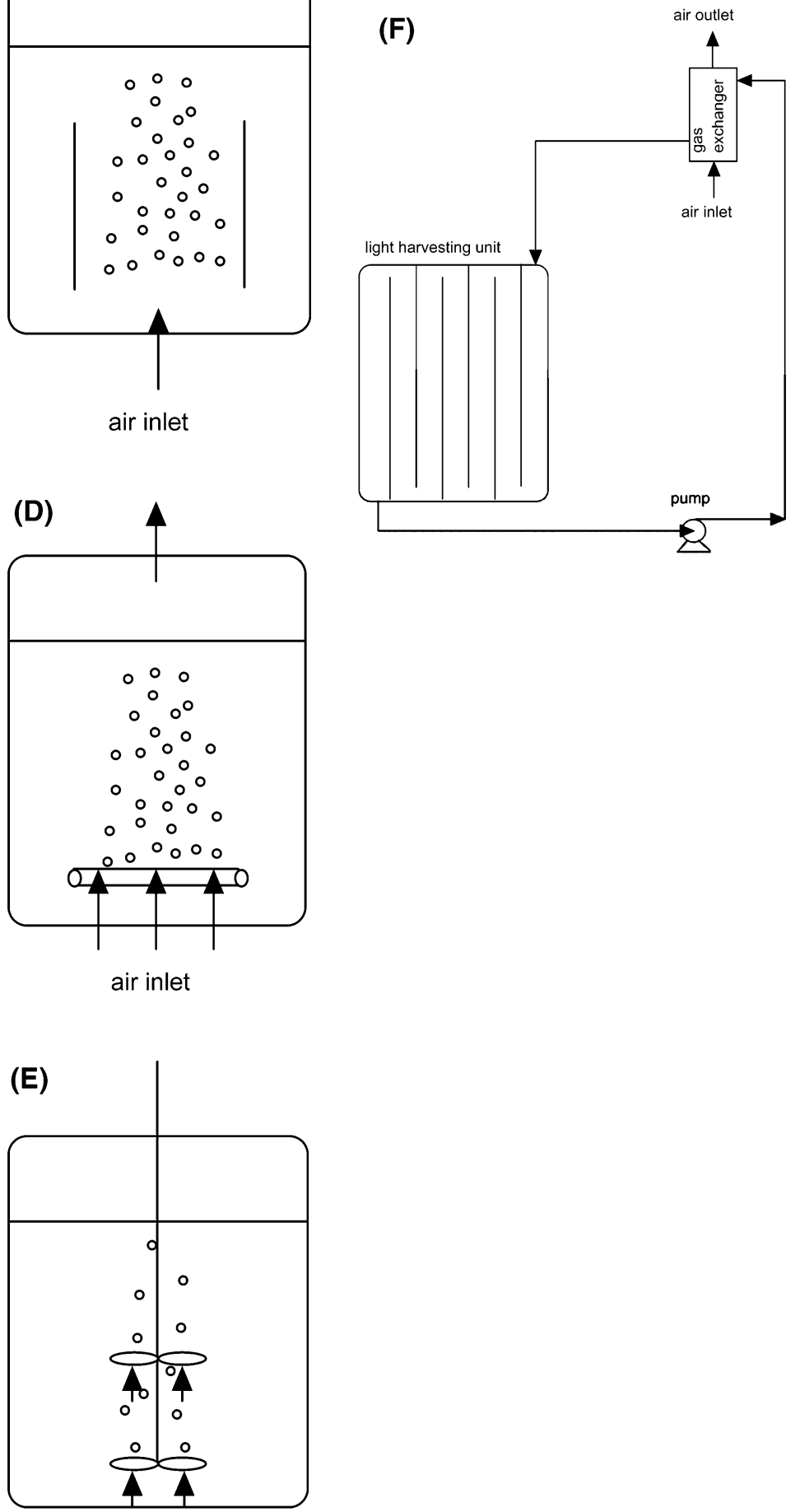

air inlet

Figure 8. Schematic representation of major methods of gas exchange in microalgal reactors: surface driven aeration (A), microporous hollowfiber membranes (B), airlift loop (C), bubble column (D), stirrer blade bubbling (E), and gas exchanger system (F).

volume of the module is typically high. Although such an indirect way of supplying $\mathrm{CO}_{2}$ by diffusion has similarities with the process described above involving silicone tubing (76), this system configuration makes it possible to use lower gas pressures, as no need to counterbalance hydrostatic heads exists (75).

According to Fick's law, mass transfer flux increases with transmembrane pressure and recirculation flow rate. Although rises in either of these operating parameters would contribute favorably, pressures are upperly constrained by mechanical limits of the equipment (typically $40 \mathrm{psi}$ ). Hence, flux enhancement usually takes advantage of increases in recirculation flow rate, whereas inlet pressure is maintained close to the maximum permitted. Use of hollow fiber devices has been reported for culture of mammalian cells (78), in culture of the microalga Chlamydomonas reinhardtii (79), in continuous culturing of the microalga $P$. tricornutum in seawater $(80)$, and in culture of the cyanobacteria Anabaena variabilis (81). 
In regard to active mode, two main transfer processes are usually considered: (i) gas mixture is circulated together with culture, either injected at a certain point of the system (riser tube) $(16,17,28,41,45,53,54,82-90)$ or bubbled at the bottom of the reactor vessel $(29-32,34-36,46,51,52,55$, $56,61-63,91,92)$; or (ii) gas is inserted into the culture when it passes through a gas exchanger $(44,50)$ (see Table 5).

Bubbling of $\mathrm{CO}_{2}$-enriched air at the bottom of the reactor is the most frequent mode of operation; it is usually performed via sintered porous stones or pipes where tiny holes were previously drilled, although gas can also be bubbled from the perforated blades of a stirrer (see Figure $8 \mathrm{C}-\mathrm{E}$ ). For larger reactor vessels, holes are usually drilled in the upper part of a long, sealed pipe, which is placed longitudinally at the bottom of the reactor. Such parameters as bubble size, gas flow rate and $\mathrm{CO}_{2}$ pressure can then be adjusted to meet the requirements of each specific culture (72). In order to avoid microalgal accumulation in certain (stagnant) areas of the bottom region, the gas stream can be injected from the sides rather than on the axis at the bottom, coupled with continuous stirring of the bottom with a magnetic stirrer (69). Unfortunately, two major drawbacks are often observed: (i) obstruction of the gas transfer devices by biofouling, which requires frequent stops for cleaning; and (ii) losses of $\mathrm{CO}_{2}$ to the atmosphere, owing to the low residence times of the gas in the culture (which increase considerably operation costs, as $\mathrm{CO}_{2}$ is an expensive utility) (21). Losses to the atmosphere can be reduced via installation of a covered sparging-diffusion system, consisting of a transparent material tightened to a frame mounted below the waterline (69); nevertheless, it is usually difficult to reach efficiencies above $10 \%$ (69). By introducing the gas directly into the circuit or via interconnected gas exchangers (see Figure $8 \mathrm{~F}$ ), it is technically possible to saturate the culture suspension. In the former situation, the gas is introduced into the circulation path and is distributed over one or more parts of the reactor (usually of tubular shape) through tiny holes. When using gas exchangers, $\mathrm{CO}_{2}$ utilization is, in principle, rather efficient because inflowing algal suspension is dispersed with a baffle plate and flows down the walls of the cylinder as a thin film, through which gas exchange can rapidly occur (69). However, this configuration is effective, in terms of adequate gas supply, only in small reactor systems. In fact, although levels of ca. $30 \mathrm{ppm}$ of $\mathrm{CO}_{2}$ on the cell surface are considered sufficient to maintain unlimited photosynthesis (69), experimental evidence has shown that, after a $100-\mathrm{m}$ path, microalgae have already used all gas available, so further gas needs to be supplied (93).

Increasing awareness of the importance of $\mathrm{CO}_{2}$ led to development of control systems, able to regulate the $\mathrm{pH}$ of the culture and thus, indirectly, control the amount of $\mathrm{CO}_{2}$ supplied. The most common system employed for $\mathrm{pH}$ control is the onoff type, in which $\mathrm{CO}_{2}$ is injected into the culture when $\mathrm{pH}$ is above a desired setpoint. However, the dynamics of the system (e.g., mixing times) do not allow a fast response to disturbances. An alternative is the use of model-based predictive control (MPC), which relies on a model able to predict the process output at future time points (horizon)-by calculating the control sequence that minimizes a certain objective function and implementing a receding strategy so that at each sampling instant the horizon is shifted toward the future. When classical on-off control was replaced by MPC (taking solar irradiance effect into account), carbon losses in tubular reactors with $P$. tricornutum were reduced from $19.7 \%$ to $5.5 \%$ (94). The main advantage of using on-off MPC instead of a classical on-off controller is the predictive capability of the former and the selection of an adequate sampling time. The use of a model to predict future behavior based on on-off signals helps to anticipate (and account for) the delay associated with a cycle time, taking also into account the on-off nature of the control signal (95). Other types of mathematical models can predict the photosynthesis rate (based on $\mathrm{O}_{2}$ generation rate and $\mathrm{CO}_{2}$ consumption rate) as a function of solar irradiance (89). Such models also permit accurate determination of the $\mathrm{CO}_{2}$ requirements of the system, thus allowing optimized use of this resource as well.

3.1.4. $\mathrm{O}_{2}$ Removal. As stressed above, light intensity is regarded as an essential issue to be addressed in microalgal systems; however, it is not the only potentially limiting factor in photosynthesis, which is chemically described by

$$
\text { energy }+\mathrm{CO}_{2}+\mathrm{H}_{2} \mathrm{O} \leftrightarrow \text { sugar }+\mathrm{O}_{2}
$$

In fact, if oxygen build-up occurs (i.e., when the concentration of dissolved oxygen in the culture is above its counterpart in equilibrium with its partial pressure in the atmosphere), the aforementioned reversible reaction is shifted to the left, thus decreasing photosynthetic efficiency; in general, oxygen concentrations above air saturation inhibit photosynthesis in microalgae (46). Besides, accumulation of $\mathrm{O}_{2}$ in the liquid culture medium is one of the most difficult problems to overcome (58), because it may become toxic above a certain threshold; dissolved oxygen concentrations above $35 \mathrm{mg} / \mathrm{L}$, which are toxic to most microalgae, were reached in outdoor cultures of Spirulina (70). This problem has not been reported in the literature pertaining to most types of small-scale culture devices, probably because the gas transfer systems employed were sufficiently powerful to provide enough carbon dioxide and promptly remove the oxygen concomitantly formed. However, when larger systems are implemented, the magnitude of said problem increases exponentially; it has even been claimed (46) to be responsible for failures in a commercial device constituted by severalkilometer-long piping.

Accumulation of photosynthetically generated oxygen becomes a particularly serious problem in high area-to-volume ratio closed photobioreactors operated outdoors; among these, HTR are described as particularly problematic. Most solutions proposed to date rely on use of a degasser (or gas exchange unit), where dissolved oxygen can be released $(17,20,51,53$, $83,87,89,90)$; however, to attain an effective separation between gas and liquid, the distance between entrance and exit of the degasser should be such that the smallest bubbles will have a sufficient time to disengage from the liquid before it leaves the unit. In closed tubular photobioreactors, in which axial gradients in concentration of gases can develop, connections between the several tubes can also incorporate a narrow tube for oxygen degassing (40). Other authors (41) tested the performance of a NHTR, essentially consisting of a layer of tubes arranged in parallel and connected by two manifolds: the lower was used to inject air into the culture, whereas the higher acted as a degasser; however, productivities were lower than expected, probably due to build-up of oxygen tension during periods of high light intensity. Especially when the exhausting gas is recirculated, accumulation of oxygen may be avoided by bubbling the exhaust gas through a sodium sulfite solution prior to its return to the reactor (11).

It should be emphasized that the aforementioned devices for oxygen degassing are only necessary when the reactor configuration does not provide an interface between culture and surrounding atmosphere, e.g., reactors with tubular or flat panel configuration. In stirred tanks and in the various bubbling-type reactors available, oxygen leaves the culture when it reaches 


\begin{tabular}{|c|c|c|c|c|c|c|c|}
\hline \multirow[b]{2}{*}{ process } & \multirow[b]{2}{*}{ type of reactor } & \multirow[b]{2}{*}{ microalga } & \multirow[b]{2}{*}{ ref } & \multicolumn{4}{|c|}{ feature } \\
\hline & & & & $\begin{array}{l}\text { mixing } \\
\text { efficiency }\end{array}$ & $\begin{array}{l}\text { gas } \\
\text { transfer }\end{array}$ & $\begin{array}{l}\text { hydrody- } \\
\text { namic stress }\end{array}$ & scale-up \\
\hline centrifugal & $\begin{array}{l}\text { system with } \\
\text { more than } \\
\text { one unit }\end{array}$ & Pumpi & & & & & \\
\hline $\begin{array}{l}\text { rotary positive displacement } \\
\text { peristaltic } \\
\text { diaphragm } \\
\text { lobe }\end{array}$ & & $\begin{array}{l}\text { C. reinhardtii } \\
\text { S. platensis }\end{array}$ & $\begin{array}{l}66 \\
29\end{array}$ & fair & low & medium & easy \\
\hline stirring with two or more blades & cylindrical tank & $\begin{array}{l}\text { Mechanical } \\
\text { filamentous }\end{array}$ & $\begin{array}{l}\text { g Mode } \\
48\end{array}$ & uniform & fair/high & high & medium \\
\hline $\begin{array}{l}\text { injection of gas } \\
\text { into culture }\end{array}$ & $\begin{array}{l}\text { air-lift } \\
\text { bubbling }\end{array}$ & $\begin{array}{l}\text { Gas Mix } \\
\text { I. galbana } \\
\text { I. galbana }\end{array}$ & $\begin{array}{l}\text { ode } \\
54 \\
20\end{array}$ & $\begin{array}{l}\text { uniform } \\
\text { fair }\end{array}$ & $\begin{array}{l}\text { high } \\
\text { fair }\end{array}$ & $\begin{array}{l}\text { low } \\
\text { low }\end{array}$ & $\begin{array}{l}\text { medium } \\
\text { medium }\end{array}$ \\
\hline
\end{tabular}

the surface, hence allowing simultaneous degassing of the whole culture. To overcome this incompatibility between a high areato-volume ratio (which characterizes tubular and flat panel reactor configurations) and efficient gas transfer (of both oxygen and carbon dioxide), a vertical alveolar panel was devised (56), in which air with extra carbon dioxide is sparged at the bottom plates and oxygen bubbles leave the liquid when they reach the top.

Since the efficiencies of all techniques used to date to provide oxygen removal from microalgal cultures are still not at a satisfactory level, a competitive mode of operation (especially in large culture systems) consists of using bubbling devices, because they eliminate the need for (the still ineffective) degassing devices. Another alternative relies on use of hollowfiber membrane apparata, as they seem to lead to lower dissolved oxygen concentrations than bubbling systems do (74). The use of several small-sized reactors instead of one larger unit may also help alleviate this problem. Nevertheless, further research should be conducted in order to accurately match the amount of $\mathrm{CO}_{2}$ supplied to the actual requirement of the growing microalga, and the amount of $\mathrm{O}_{2}$ removed to the actual amount of $\mathrm{O}_{2}$ produced.

In view of the above, one concludes that there is no universally optimum gas transfer device; the choice of the most suitable one depends on the microalga considered and the objective function preselected.

3.2. Mixing. After fulfillment of nutritional growth requirements and assurance that environmental factors are non-limiting, mixing becomes a critical parameter. In reactor configurations that consist of more than one vessel (e.g., a carbonation tower for gas exchange, coupled to one or several tubes for light supply), adequate mixing is particularly required in order to recirculate the culture between vessels. Even in the case of single vessel reactors, efficient mixing should be provided in order to produce a uniform dispersion of microalgae within the culture medium, thus eliminating gradients of light, nutrient concentration (including $\mathrm{CO}_{2}$ ) and temperature; note that thermal amplitudes of up to $8{ }^{\circ} \mathrm{C}$ have been recorded between the top and bottom of unmixed cultures, leading to irreversible damage (96). Finally, the effect of "mutual shading", i.e., continuous cell movement from and to dark/light zones, has been claimed (69) to be essential to guarantee high biomass productivity. In a dense culture, the region where microalgae receive enough light for photosynthesis can be quite shallow $(2-5 \mathrm{~cm})(69)$, so vigorous mixing is necessary to provide cells with a uniform average exposure to light.

Current mixing techniques are often insufficient to attain the aforementioned requirements, because the induced turbulence is random, i.e., not all algal cells are submitted to a uniform pattern of movement into and out of the illuminated area of the reactor. Furthermore, mixing should be supplied to proper extents, because very low values promote settling and hence emergence of dead zones (especially toward the bottom of the reactor) where anaerobic conditions prevail, thus leading to cell deterioration and consequent decrease of productivity; in the limit, toxic compounds will form that might compromise viability of the whole culture $(69,70)$. Inadequate mixing also permits clumping of cells into aggregates of varying sizes, hence leading to development of a three-phase system (gas/liquid/solid) inside the reactor, which is prone to decreasing mass transfer rates (6). On the other hand, high mixing rates may lead to shearinduced injury of cells $(22,23)$, which hamper their viability. The most important mechanism of cell damage in sparged cultures agitated at low intensities is bubble break-up at the liquid-gas interface (i.e., microalgal cells are captured by the rising gas bubbles and carried to the surface, where they die as bubbles collapse). At higher agitation intensities, cell damage caused by fluid-mechanical stress acquires a greater significance as the specific aeration rate decreases (97).

The major mixing/recirculation systems commercially used are described in Table 6 . They can be tentatively divided in pumping (used when more than one vessel is present), mechanical stirring (usually present when only one vessel is used) and gas mixing (which takes advantage of a gas, usually $\mathrm{CO}_{2}$ enriched air, injected in the culture to promote turbulent mixing and recirculation through the various vessels). Combinations of these systems are also possible. Former recirculation systems used exclusively pumps, either centrifugal, positive displacement, peristaltic or diaphragm ones. As research progressed, it was soon realized that cultures recirculated with distinct pumping apparata attained different maximum specific growth rates, and that the adverse effects caused by centrifugal and rotary positive displacement pumps were essentially proportional to their rotation speeds (38). The extent of damage observed in various pumps was accordingly measured as a function of the number of passes of algal suspension through the pumps in a closed loop, and the concept of hydrodynamic stress was thus introduced, which provided a framework to assess parameters that determine magnitude of shear stress phenomena: geometry of the reactor, type of pump involved, and morphological and physiological conditions of the microalga $(22,24,25)$.

Gas mixing systems, i.e., bubble column systems, cause less extensive damage to fragile microalgal species than mechanical pumping does. This is especially the case of air-lift units, in which mixing is achieved by fluid flow obtained from sparging air into a central draught tube (riser), where it decreases bulk 
liquid density hence causing the liquid to rise. The liquid then flows downward through the outer tube, thus creating a natural circulation. Although these systems appear to cause the least extensive degree of cell damage (21), they are not completely devoid of shear stress: a cell-damaging hydrodynamic effect has been reported (46) in bubble columns and airlift reactors, which was associated with so intense turbulence patterns that the length scale of the fluid microeddies approached cellular dimension. Barbosa (26) reported bubble formation at the sparger as the main event leading to cell death. Furthermore, increasing cell density leads to extra difficulties in producing homogeneous cultures, so the need to provide mechanical agitation arises (associated with lower speeds, so as to keep shear stress to a minimum) (98). Subsequent studies on the influence of increasing power supply on decreasing of microeddy length scale demonstrated that this scale was always much higher than cell size, and therefore shear stress rather than turbulence was responsible for the existence of stress phenomena (27). Extra stirrers may provide such a mechanical agitation, with one or more blades. Another alternative lies in the introduction of baffles along the culture path, so as to create a controlled turbulence pattern. Degen (99) used horizontal baffles to subdivide the riser on a flat panel airlift photo-bioreactor, thus creating a defined circulation path and exposing the cells to intermittent light, hence creating a flashing-light effect.

When the reactor configuration corresponds to only one vessel, the microalgal suspension can be agitated by means of a stirrer, which usually consists of a central tube with two or more blades. In order to enhance mixing without damaging cells, a hybrid configuration has also been described (69) in which a stream of $\mathrm{CO}_{2}$-enriched air is passed via the central tube into the blades, from where it penetrates the medium through capillary holes. This mixing device is the most usual in cylindrical bioreactors.

As distinct microalgae have different sensitivities to shear, there is no single optimum mixing system for all microalgal species; the microorganism in use will again be the determinant issue when evaluating mechanical and hydrodynamic shear effects that are admissible during regular operation of the photobioreactor.

3.3. Light Requirement. Light is the basic energy source for photo-autotrophic organisms, as microalgae are; hence, their light harvesting efficiency is of crucial importance for bioreactor engineering encompassing those microrganisms. The photosynthetically active radiance (PAR) is normally assumed to be ca. $43-45 \%$ in the wavelength range $400-700 \mathrm{~nm}(100,101)$. The photosynthetic efficiency (PE) is defined as the fraction of available light that is eventually stored as chemical energy in biomass; however, there is no general consensus on how to calculate its actual value. Note that PE is a theoretical upper limit. In practice, especially in long-term cultures, $\mathrm{PE}$ is normally below $6.5 \%$, and under optimal conditions, only $40 \%$ of the theoretical maximum yields can typically be reached (86). Hence, increase in PE is likely the best approach in attempts to enhance microalga productivity, which is a sine qua non condition to guarantee commercial competitiveness of the associated bioprocess.

In order to estimate PE for a selected species in a given reactor, one departs from calculation of the illuminated surface area per unit volume of the culture, $A v$; in the case of a VTR (probably the most popular reactor configuration), one has (53)

$$
A v=2 \frac{r_{\mathrm{o}}}{\pi \cdot r^{2}}
$$

where $r$ and $r_{\mathrm{o}}$ are the inner and outer radius of the tubes, respectively, provided that the tubes hold no gaps between them.

Applying the well-studied microbial-growth energy equation, after the reasoning detailed by Pirt (83), one is led to

$$
q=\frac{\mu}{Y_{\mathrm{G}}}+m
$$

where $q$ is the specific rate of light uptake, $\mu$ is the specific rate of growth, $Y_{G}$ is the maximum growth yield on light, and $m$ is the maintenance coefficient. The value of $q$ may, in turn, be calculated via

$$
q=\frac{\phi \cdot I_{0} \cdot A v}{X}
$$

where $\phi$ is the fraction of photosynthetically available light, $I_{\mathrm{O}}$ is the total incident irradiance, and $X$ is the biomass concentration.

Combining eqs 4 and 5 and assuming a light-limited culture with a maintenance coefficient virtually nil, one obtains the biomass output rate $(\mu \cdot X)$ as

$$
\mu \cdot X=\phi \cdot I_{\mathrm{o}} \cdot Y_{\mathrm{G}} \cdot A v
$$

In a reactor operated under a constant $A v$ and a given $I_{\mathrm{o}}$, it is possible to adjust $\mu$ and $X$ (eq 6 ) so as to achieve the maximum biomass yield $\left(Y_{\mathrm{G}}\right)$, which then also leads to the maximum PE (83).

If a proper reactor design is sought, it is crucial to obtain the maximum biomass yield at the expense of the light actually available. The latter parameter depends on the reactor configuration and location. If one considers reactors illuminated by direct sunlight, the maximum $I_{\mathrm{o}}$ depends on the latitude of the facility, so it can be controlled only by changing the reactor inclination toward sunlight (28). Several reactors have indeed been developed or tuned accordingly (59). On the other hand, in artificially illuminated reactors, the maximum $I_{\mathrm{o}}$ depends on the nature, intensity and relative position of the light source, all of which can be accurately manipulated and controlled.

Most reactors are normally designed so as to exhibit a high $A v$; it is thus possible to work at higher biomass concentration for a given yield $\left(Y_{\mathrm{G}}\right)$. Good examples of reactors designed to harvest the maximum light are the alveolar panel reactor by Tredici (59), and the tubular reactors by Grima (45), Richmond (17) and Zittelli (41). Reactors that combine natural and artificial lights have also been described $(3,62)$. In terms of artificially illuminated reactors, the need of small diameters to increase $A v$ can be circumvented via provision of internal illumination. The higher biomass yield $\left(Y_{\mathrm{G}}\right)$ can be even more important in the case of artificially illuminated reactors, as the light provided represents a cost itself that adds to the overall running costs of the process. Nevertheless, such cost may be kept limited, as the latest few years have witnessed the development of methods for in situ growth monitoring-from flow injection analysis systems based on turbidimetric measurements (68) to techniques based on real-time monitoring and control of biomass by using light transmittance sensors (102).

The light energy available for each microalga cell $\left(I_{\mathrm{av}}\right)$ depends on several factors, e.g., $I_{\mathrm{o}}$ and biomass concentration. Several authors (103) have demonstrated that increasing light intensity increases growth rate, but only until a saturation point is reached. Above this threshold, increasing light produces no positive effect on growth rate, hence generating a dramatic decrease in $Y_{\mathrm{G}}$, as a major fraction of light cannot be used by 
Table 7. Generic Description of Methods for Light Supply in Photo-Bioreactors

\begin{tabular}{llcccc}
\hline & \multicolumn{4}{c}{ feature } \\
\cline { 2 - 5 } mode & cost & intensity control & land area required & reactor design & productivity \\
\hline sunlight & small & problematic & high & must be designed for high & depends on weather \\
and latitude & surface/volume ratio & allows great flexibility & constant
\end{tabular}

the culture. Furthermore, the light will influence not only biomass productivity, but also its biochemical profile $(15,19$, 45, 64-67).

An interesting method to assess $I_{\mathrm{av}}$ on tubular reactors, based on $I_{\mathrm{o}}$ and $X$, was developed by Evers (104) and later applied by Grima (64). This model assumes that light attenuation caused by mutual shading is dependent on Beer-Lambert law, which calculates the light available at each single point at a given distance from the surface, followed by integration on both the cross sectional and the outer surface areas. Use of this model allows one to fit $I_{\mathrm{O}}$ in order to work below the saturation point, hence avoiding a decrease in $Y_{G}$ and/or an adjustment of $I_{\text {av }}$ for a more consistent biochemical profile.

Sunlight and artificial illumination data are compared in Table 7. The source of artificial illumination is of crucial importance, because the wavelength spectrum should be specific in order to take full advantage of the total $I_{\mathrm{o}}$ made available. As seen before, PAR lies within the wavelength range 400-700 nm, so a lamp with a vast spectrum and with its maximum radiation in that range is normally chosen. However, different lamps will generate distinct spectra; on the other hand, each microalga species possesses its own absorption optimum, so each individual case must be studied per se. You and Barnett (105) related a dependence of the exponential growth rates on the energy of radiation and spectrum of light, and concluded that blue light (400-500 nm) increased cell growth and polysaccharide production in $P$. cruentum.

The method to evaluate the efficiency of conversion, described by Simmer (106), takes into account the photon flux $(P)$ emitted by the lamp in the PAR wavelength, the specific absorption coefficient of each species and the quantum capacity, hence allowing one to estimate the efficiency of conversion according to

$$
E R F=\int P(\lambda) d \lambda
$$

where ERF is the emitted radiant flux, which is a function of the wavelength, $\lambda$.

\section{Conclusions}

It is our belief that long-term trends of research in the field of microalgae should encompass design and development of reactor systems, as well as microalgal strains able to increase specific metabolite productivity.

Whereas open raceway ponds are presently the primary systems used in commercial production of microalgal biomass outdoors, there is not a single recommended design in what concerns closed systems. Closed systems are indeed more complex than their open counterparts, thus requiring improved technological skills to operate them and higher investment costs to house them; otherwise, they possess the advantage of more accurate control of various parameters during regular operation, hence enhancing productivities.

The main challenge to the microalga research community now appears to lie on the design of a closed system so effective in biomass and metabolite productivity that it will eventually overcome the extra investment cost required, and thus become profitable and fully competitive.

To attain maximum productivity, several parameters are to be controlled, viz., sufficient nutrient level and optimum temperature and $\mathrm{pH}$ (topics not covered here, owing to limitation of space), as well as adequate mixing and turbulence, coupled with provision for oxygen degassing and light control (which were the focus of this specific review). From the many reactor configurations built to date (viz., HTR, VTR, HeTR, FPR and FTR), none is able to effectively control all of those parameters simultaneously. Some are indeed optimized for better sunharvesting capacity, but scale-up is not suitable; conversely, others can be better controlled, but sun-harvesting efficiency becomes poor.

On the other hand, since continuous supply of $\mathrm{CO}_{2}$ to microalgal cultures is expensive, it is necessary to provide devices that supply it in a discontinuous fashion. In fact, during the first few hours (or days, depending on the duration of the lag phase) following inoculation of a batch culture, there is a large amount of $\mathrm{CO}_{2}$ dispersed in the medium; during the exponential growth phase, essentially all $\mathrm{CO}_{2}$ supplied is used up; and finally, in the stationary phase, the rate of utilization of $\mathrm{CO}_{2}$ declines again. The supply of $\mathrm{CO}_{2}$ to the medium is in general controlled via monitoring $\mathrm{pH}$; nevertheless, such underlying relationship may lead to erroneous values due to the influence of other dissolved ions on $\mathrm{pH}$. Consequently, it would be more correct to measure $\mathrm{CO}_{2}$ directly with a probe or to choose another parameter closely related therewith. Maximization of $\mathrm{CO}_{2}$ transfer may proceed via hollow-fiber membranes, which enhances mass transfer and decreases costs, by recirculating unused gas and using lower gas pressures.

In scale-up of culture devices, some of the conditions that were easily controlled at a small scale may become difficult problems. One such situation concerns degassing of oxygen, which is believed to be responsible for failure of commercial devices. There is not a single, straightforward solution, and a feasible approach consists of using several small units for growth rather than one larger unit. In this way, the various units may function separately (depending on the production needs), and the gaseous transfers will be more efficient, while minimizing $\mathrm{O}_{2}$ build-up. However, economic studies should be performed, in order to adequately evaluate the feasibility of this solution. When using hollow-fiber membrane devices to bring about exchange of gases within the culture, the content of dissolved oxygen was found to be lower than with the bubbling system, so it may constitute a suitable alternative in terms of gaseous changes. Another approach relies on use of bubbling devices, as they eliminate the need for (the still ineffective) degassing devices.

Concerning light intensity, operational issues are also not clear cut. On the one hand, use of sunlight is cheaper but the light cycle cannot be controlled, which often precludes higher biomass productivities. On the other hand, artificially illuminated reactors are typically expensive. The use of optical fibers (contaminated with impurities that will lead to gradual dispersion of light) that can introduce light inside reactors with large volumes and effective monitoring of the light available for photosynthesis 
will probably constitute a breakthrough-that will eventually turn closed reactors into fully competitive options.

In the past few years, studies on photo-bioreactor sensing have also appeared, which presented innovative approaches to assess photobioreactor states, hence allowing estimation of such parameters as biomass density, specific growth rate, dissolved oxygen concentration, photosynthetic efficiency and average light intensity (107). Such type of control is expected to help in decreasing operation costs. In addition, the continuous reuse of biomass for harvesting of high-value compounds from microalgae ("milking of microalgae") has also been addressed as a potential technology of production (108). Although such a method has been employed for the production of $\beta$-carotene from $D$. salina, it is not applicable to all strains or products. Studies on the physiological behavior of cells, particularly cell membranes (among others), are still necessary before developing a generic "milking" process.

Finally, the intrinsic characteristics of the microalgae selected for use should also guarantee technological suitability. Selection of strains should thus emphasize such features as specific growth rate, tendency to clump and settle, ability to foam, adherence to container walls, and shear and temperature sensitivities. In addition, existing species should be carefully screened in order to select the most performant strains, which hold the capacity to overproduce specific end products with a market value. The performance of those species could be even reinforced via genetic engineering, using tools already available.

\section{Acknowledgment}

Mrs. Gisela Oliveira is hereby gratefully acknowledged for her kind help in bibliographic search. Financial support for A.P.C. (grant BD/2838/93-IF) and L.A.M. (grant BD/15890/ 98-FCT) by PRAXIS XXI (Portugal) is also to be noted. Partial funding was obtained from a project grant (MICROPESCA/ 0072/04), issued by program MARE (Portugal).

\section{References and Notes}

(1) Soeder, C. J. A historical outline of applied algology. In Handbook of Microalgal Mass Culture; Richmond, A., Ed.; CRC Press: Boca Raton, FL, 1986; pp 25-41.

(2) Burlew, J. Current status of the large-scale culture of algae. In Algal Culture: From Laboratory to Pilot Plant; Burlew, J. S., Ed.; Carnegie Institution of Washington Publications: Washington, DC, 1976; pp 3-23.

(3) Chaumont, D. Biotechnology of algal biomass production: a review of systems for outdoor mass culture. J. Appl. Phycol. 1993, 5, 593604.

(4) Borowitzka, M. A. Microalgae for aquaculture: Opportunities and constraints. J. Appl. Phycol. 1997, 9, 393-401.

(5) Yamaguchi, K. Recent advances in microalgal bioscience in Japan, with special reference to utilization of biomass and metabolites: A review. J. Appl. Phycol. 1996, 8, 487-502.

(6) Panda, A. K.; Mishra, S.; Bisaria, V. S.; Bhojwani, S. S. Plant cell reactors-a perspective. Enzyme Microb. Technol. 1989, 11, 386-397.

(7) Wang, G.; Chen, H.; Li, G.; Chen, L.; Li, D.; Hu, C.; Chen, K.; Liu, Y. Population growth and physiological characteristics of microalgae in a miniaturized bioreactor during space flight. Acta Astronautica 2006, 58, 264-269.

(8) Travieso, L.; Pellón, A.; Benítez, F.; Sánchez, E.; Borja, R.; O’ Farrill, N.; Weiland, P. BIOALGA reactor: preliminary studies for heavy metal removal. Biochem. Eng. J. 2002, 12, 87-91.

(9) Scragg, A. H.; Illman, A. M.; Carden, A.; Shales, S. W. Growth of microalgae with increased calorific values in a tubular bioreactor. Biomass Bioenergy 2002, 23, 67-73.

(10) Nagase, H.; Yoshihara, K.; Eguchi, K.; Okamoto, Y.; Murasaki, S.; Yamashita, R.; Hirata, K.; Miyamoto, K. Uptake pathway and continuous removal of nitric oxide from flue gas using microalgae. Biochem. Eng. J. 2001, 7, 241-246.
(11) Acién-Fernández, F. G.; Férnandez-Sevilla, J. M.; EgorovaZachernyuk, T. A.; Molina-Grima, E. Cost-effective production of ${ }^{13} \mathrm{C},{ }^{15} \mathrm{~N}$ stable isotope-labelled biomass from phototrophic microalgae for various biotechnological applications. Biomol. Eng. 2005, 22, 193-200.

(12) Borowitzka, M. A. Commercial production of microalgae: ponds, tanks, tubes and fermenters. J. Biotechnol. 1999, 70, 313-321.

(13) Becker, C. C.; Kyle, D. J. Developing functional foods containing algal docosahexaenoic acid. Food Technol. 1998, 52, 68-71.

(14) Markl, $\mathrm{H} . \mathrm{CO}_{2}$ transport and photosynthetic productivity of a continuous culture of algae. Biotechnol. Bioeng. 1977, 19, 18511862.

(15) Grima, E. M.; Fernández, F. G. A.; Camacho, F. G.; Chisti, Y. Photobioreactors: light regime, mass transfer, and scaleup. $J$. Biotechnol. 1999, 70, 231-247.

(16) Pulz, O. Open-air and semi-closed cultivation systems for the mass cultivation of microalgae. In First Asia-Pacific Conference on Algal Biotechnology, Kuala Lumpur, Malaysia, 1992.

(17) Richmond, A.; Boussiba, S.; Vonshak, A.; Kopel, R. A new tubular reactor for mass production of microalgae outdoors. J. Appl. Phycol. 1993, 5, 327-332.

(18) Chrismada, T.; Borowitzka, M. A. Growth and lipid production of Phaeodactylum tricornutum in a tubular photobioreactor. In Algal Biotechnology in the Asia-Pacific Region, Kuala Lumpur, Malaysia, 1994.

(19) Grima, E. M.; Perez, J. A. S.; Camacho, F. G.; Fernandez, F. G. A.; Sevilla, J. M. F.; Sanz, F. V. Effect of dilution rate on eicosapentaenoic acid productivity of Phaeodactylum tricornutum Utex-640 in outdoor chemostat culture. Biotechnol. Lett. 1994, 16 , $1035-1040$.

(20) Travesio, L.; Hall, D. O.; Rao, K. K.; Benítez, F.; Sánchez, E.; Borja, R. A helical tubular reactor producing Spirulina in a semicontinuous mode. Int. Biodeterg. Biodegrad. 2001, 47, 151155.

(21) Borowitzka, M. A. Closed algal photobioreactors: design considerations for large-scale systems. J. Mar. Biotechnol. 1996, 4, 185191.

(22) Gudin, C.; Chaumont, D. Cell fragility-the key problem of microalgae mass production on closed photobioreactors. Bioresour. Technol. 1991, 38, 145-151.

(23) Thomas, W. H.; Gibson, C. H. Effects of small-scale turbulence on microalgae. J. Appl. Phycol. 1990, 2, 71-77.

(24) Jaouen, P.; Vandanjon, L.; Quéméneur, F. The shear stress of microalgal cell suspensions (Tetraselmis suecica) in tangential flow filtration systems: the role of pumps. Bioresour. Technol. 1999, 68, $149-154$

(25) Vandanjon, L.; Rossignol, N.; Jaouen, P.; Robert, J. M.; Quéméneur, F. Effects of shear on two microalgae species. Contribution of pumps and valves in tangential flow filtration systems. Biotechnol. Bioeng. 1999, 63, 1-9.

(26) Barbosa, M. J.; Hadiyanto; Wijffels, R. H. Overcoming shear stress of microalgae cultures in sparged photobioreactors. Biotechnol. Bioeng. 2004, 85, 78-85.

(27) Alías, C. B.; López, M. C. G. M.; Fernández, F. G. A.; Sevilla, J. M. F.; Sánchez, J. L. G.; Grima, E. M. Influence of power supply in the feasibility of Phaeodactylum tricornutum cultures. Biotechnol. Bioeng. 2004, 87, 723-733.

(28) Lee, Y. K.; Ding, S. Y.; Low, C. S.; Chang, Y. C. Design and performance of an $\alpha$-type tubular photobioreactor for mass cultivation of microalgae. J. Appl. Phycol. 1995, 7, 47-51.

(29) Laing, I.; Jones, E. A turbidostat vessel for the continuous culture of marine microalgae. Aquacult. Eng. 1988, 7, 89-96.

(30) Trotta, P. A simple and inexpensive system for continuous monoxenic mass culture of marine microalgae. Aquaculture 1981, $22,383-387$.

(31) Cohen, E.; Arad, S. M. A closed system for outdoor cultivation of Porphyridium. Biomass 1989, 18, 59-67.

(32) Martínez-Jerónimo, F.; Espinosa-Chavez, F. A laboratory-scale system for mass culture of freshwater microalgae in polyethylene bags. J. Appl. Phycol. 1994, 6, 423-425.

(33) Tredici, M. R.; Rodolfi, L. University of Florence, Italy. Reactor for industrial culture of photosynthetic micro-organisms. PCT WO 2004/074423 A2, 2004. 
(34) Chae, S. R.; Hwang, E. J.; Shin, H. S. Single cell protein production of Euglena gracilis and carbon dioxide fixation in an innovative photo-bioreactor. Bioresour. Technol. 2006, 97, 322329.

(35) Miyamoto, K.; Wable, O.; Benemann, J. R. Vertical tubular reactor for microalgae cultivation. Biotechnol. Lett. 1988, 10, 703-708.

(36) James, C. M.; al-Khars, A. M. An intensive continuous culture system using tubular photobioreactors for producing microalgae. Aquaculture 1990, 87, 381-393.

(37) Fukami, K.; Nishimura, S.; Ogusa, M.; Asada, M.; Nishijima, T. Continuous culture with deep seawater of a benthic food diatom Nitzchia sp. Hydrobiology 1997, 358, 245-249.

(38) Lee, Y. K. Enclosed bioreactors for the mass cultivation of photosynthetic microorganisms: the future trend. TIBTECH 1986, July, 186-189.

(39) Richmond, A. The challenge confronting industrial microagriculture: high photosynthetic efficiency in large-scale reactors. Hydrobiology 1987, 151/152, 117-121.

(40) Torzillo, G.; Puspararaj, B.; Bocci, F.; Balloni, W.; Materassi, R.; Florenzano, G. Production of Spirulina biomass in closed photobioreactors. Biomass 1986, 11, 61-74.

(41) Zittelli, G. C.; Lavista, F.; Bastianini, A.; Rodolfi, L.; Vincenzini, M.; Tredici, M. R. Production of eicosapentaenoic acid by Nannochloropsis sp. cultures in outdoor tubular photobioreactors. $J$. Biotechnol. 1999, 70, 299-312.

(42) Olaizola, M. Commercial production of astaxanthin from Heamatococcus pluvialis using 25,000 liter outdoor photobioreactors. J. Appl. Phycol. 2000, 12, 499-506.

(43) Gudin, C.; Chaumont, D. Solar biotechnology study and development of tubular solar receptors for controlled production of photosynthetic cellular biomass for methane production and specific exocellular biomass. Sol. Energy R\&D Eur. Community, Ser. E 1984, 5, 184-193.

(44) Chaumont, D.; Thepenier, C.; Gudin, C.; Junjas, C. Scaling up a tubular photobioreactor for continuous culture of Porphyridium cruentum from laboratory to pilot plant (1981-1987). In Algal Biotechnology; Stadler, T., Mollion, J., Verdus, M.-C., Karamanos, Y., Morvan, H., Christiaen, D., Eds.; Elsevier: New York, 1988; pp 199-208.

(45) Grima, E. M.; Pérez, J. A. S.; Camacho, F. G.; Sánchez, J. L. G.; Fernández, F. G. A.; Alonso, D. L. Outdoor cultivation of Isochrysis galbana ALII-4 in a closed tubular photobioreactor. J. Biotechnol. 1994, 37, 159-166.

(46) Mirón, A. S.; Gómez, A. C.; Camacho, F. G.; Grima, E. M.; Chisti, Y. Comparative evaluation of compact photobioreactors for largescale monoculture of microalgae. J. Biotechnol. 1999, 70, 249270.

(47) Tredici, M. R.; Zittelli, G. C. Efficiency of sunlight utilization: tubular versus flat photobioreactors. Biotechnol. Bioeng. 1998, 57, 187- 197.

(48) Tredici, M. R. Closed photobioreactors: basic and applied aspects. In Proceedings of Marine Biotechnology: Basics and Applications, Matalascañas, Spain, 2003; p 1.

(49) Robinson L. F.; Morrison A. W.; Bamforth M. R. Improvements relating to biosynthesis. European Patent 261,872, 1988.

(50) Chrismada, T.; Borowitzka, M. A. Effect of cell density and irradiance on growth, proximate composition and eicosapentaenoic acid production of Phaeodactylum tricornutm grown in a tubular photobioreactor. J. Appl. Phycol. 1994, 6, 67-74.

(51) Morita, M.; Watanable, Y.; Saiki, H. Investigation of photobioreactor design for enhancing the photosynthetic productivity of microalgae. Biotechnol. Bioeng. 2000, 69, 693-698.

(52) Morita, M.; Watanable, Y.; Okawa, T.; Saiki, H. Photosynthetic productivity of conical helical tubular photobioreactors incorporating Chlorella sp. under various culture medium flow conditions. Biotechnol. Bioeng. 2001, 74, 135-144.

(53) Pirt, S. J.; Lee, Y. K.; Walach, M. R.; Pirt, M. W.; Balyuzi, H. H. M.; Bazin, M. J. A tubular bioreactor for photosynthetic production of biomass from carbon-dioxide-design and performance. J. Chem. Technol. Biotechnol. B 1983, 33, 35-58.

(54) Richmond, A.; Cheng-Wu, Z. Optimization of a flat plate glass reactor for mass production of Nannochloropsis sp. outdoors. J. Biotechnol. 2001, 85, 259-269.
(55) Iqbal, M.; Grey, D.; Stepan-Sarkissian, F.; Fowler, M. W. A flatsided photobioreactor for continuous culturing microalgae. Aquaculture Eng. 1993, 12, 183-190.

(56) Tredici, M. R.; Carlozzi, P.; Zittelli, G. C.; Materassi, R. A vertical alveolar panel (VAP) for outdoor mass cultivation of microalgae and cyanobacteria. Bioresour. Technol. 1991, 38, 153-159.

(57) Tredici, M. R.; Materassi, R. From open ponds to vertical alveolar panels: the Italian experience in the development of reactors for the mass cultivation of phototrophic microorganisms. J. Appl. Phycol. 1992, 4, 221-231.

(58) Tredici, M. R.; Zittelli, G. C.; Biagiolini, S.; Materassi, R. Novel photobioreactor for the mass cultivation of Spirulina spp. Bull. Inst. Oceanogr. 1993, 89-96.

(59) Tredici M. R. Bioreactors, photo. In Encyclopedia of Bioprocess Technology: fermentation, biocatalysis and bioseparation; Flickinger, M.C., Drew, S.W., Eds.; Wiley: New York, 1999; Vol 1, pp 395-419.

(60) Puspararaj, B.; Pelosi, E.; Tredici, M. R.; Pinzani, E.; Materassi, R. An integrated culture system for outdoor production of microalgae and cyanobacteria. J. Appl. Phycol. 1997, 9, 113-119.

(61) Pohl, P.; Kohlhase, M.; Martin, M. Photobioreactors for the axenic mass cultivation of microalgae. In Algal Biotechnology; Stadler, T., Mollion, J., Verdus, M.-C., Karamanos, Y., Morvan, H., Christiaen, D., Eds.; Elsevier: New York, 1988; pp 209-218.

(62) Ogbonna, J. C.; Soejima, T.; Tanaka, H. An integrated solar and artificial light system for internal illumination of photobioreactors. J. Biotechnol. 1999, 70, 289-297.

(63) Eriksen, N. T.; Geest, T.; Iversen, J. J. L. Phototrophic growth in the lumostat: a photo-bioreactor with on-line optimization of light intensity. J. Appl. Phycol. 1996, 8, 345-352.

(64) Grima, E. M.; Perez, J. A. S.; Camacho, F. G.; Sanchez, J. L. G.; Alonso, D. L. n-3 PUFA productivity in chemostat cultures of microalgae. Appl. Microbiol. Biotechnol. 1993, 38, 599-605.

(65) Grima, E. M.; Camacho, F. G.; Perez, J. A. S.; Sanchez, J. L. G. Biochemical productivity and fatty acid profiles of Isochrysis galbana Parke and Tetraselmis sp. as a function of incident light intensity. Process Biochem. 1994, 29, 119-126.

(66) Grima, E. M.; Perez, J. A. S.; Camacho, F. G.; Sevilla, J. M. F.; Fernandez, F. G. A. Effect of growth-rate on the eicosapentaenoic acid and docosahexaenoic acid content of Isochrysis galbana in chemostat culture. Appl. Microbiol. Biotechnol. 1994, 41, 23-27.

(67) Grima, E. M.; Camacho, E. G.; Perez, J. A. S.; Fernandez, E. G. A.; Sevilla, J. M. F. Growth yield determination in a chemostat culture of the marine microalga Isochrysis galbana. J. Appl. Phycol. 1996, 8, 529-534.

(68) Meireles, L. A.; Azevedo, J. L.; Cunha, J. P.; Malcata, F. X. Online determination of biomass in a microalga bioreactor using a novel computerized flow injection analysis system. Biotechnol. Prog. 2002, 18, 1387-1391.

(69) Becker, E. W. Large-scale cultivation. In Microalgae: Biotechnology and Microbiology; Becker, E. W., Ed.; Cambridge University Press: New York, 1994; pp 63-171.

(70) Richmond, A. Technological aspects of mass cultivation-a general outline. In CRC Handbook of Microalgal Mass Culture; Richmond, A., Ed; CRC Press: Boca Raton, FL, 1986; pp 245-264.

(71) Goldman, J. C.; Dennett, M. R.; Riley, C. B. Inorganic carbon sources and biomass regulation in intensive microalgal cultures. Biotechnol. Bioeng. 1981, 23, 995-1014.

(72) Talbot, P.; Gortares, M. P.; Lencki, R. W.; de la Noue, J. Absorption of $\mathrm{CO}_{2}$ in algal mass culture systems: a different characterization approach. Biotechnol. Bioeng. 1991, 37, 834-842.

(73) Grima, E. M.; Sanchez-Perez, J. A.; Garcia-Camacho, F.; RoblesMedina, A. Gas-liquid transfer of atmospheric $\mathrm{CO}_{2}$ in microalgal cultures. Chem. Technol. Biotechnol. 1993, 56, 329-337.

(74) Ferreira, B. S.; Fernandes, H. L.; Reis, A.; Mateus, M. Microporous hollow fibres for carbon dioxide absorption: mass transfer model fitting and the supplying of carbon dioxide to microalgal cultures. Chem. Technol. Biotechnol. 1998, 71, 61-70.

(75) Carvalho, A. P.; Malcata, F. X. Transfer of carbon dioxide within cultures of microalgae: plain bubbling versus hollow-fiber modules. Biotechnol. Prog. 2001, 17, 265-272.

(76) Lee, Y.-K.; Hing, H.-K. Supplying $\mathrm{CO}_{2}$ to photosynthetic algal cultures by diffusion through gas-permeable membranes. Appl. Microbiol. Biotechnol. 1989, 31, 298-301. 
(77) Aunins, J. G.; Henzler, H. Aeration in cell culture bioreactors. In Biotechnology; Stephanopoulos, G., Ed.; Wiley-VCH: Weinheim, 1993; Vol. 3 (Bioprocessing), p 223.

(78) Gallagher, S. L.; Tharakan, J. T.; Chau, P. C. An intercalatedspiral wound hollow fiber bioreactor for the culture of mammalian cells. Biotechnol. Tech. 1987, 1, 91-96.

(79) Chen, F.; Johns, M. R. A strategy for high cell density culture of heterotrophic microalgae with inhibitory substrates. J. Appl. Phycol. 1995, 7, 43-46.

(80) Marsot, P.; Cembella, A. D.; Mouhri, K. Croissance de la biomasse azotée du Phaeodactylum tricornutum (Bacillariophyceae) en culture discontinue dialysante et non-dialysante. Can. J. Microbiol. 1992, 38, 945-952.

(81) Markov, S. A.; Bazin, M. J.; Hall, D. O. Hydrogen photoproduction and carbon dioxide uptake by immobilized Anabaena variabilis in a hollow-fiber photobioreactor. Enzyme Microb. Technol. 1995, 17, 306-310.

(82) Pirt, S. J.; Panikov, N.; Lee, Y.-K. The miniloop: a small-scale air-lift microbial culture vessel and photobiological reactor. J. Chem. Technol. Biotechnol. 1979, 29, 437-441.

(83) Pirt, S. J. Microbial photosynthesis in the harnessing of solarenergy. J. Chem. Technol. Biotechnol. 1982, 32, 198-202.

(84) Laws, E. A.; Terry, K. L.; Wickman, J.; Chalup, M. S. A simple algal production system designed to utilize the flashing light effect. Biotechnol. Bioeng. 1983, 25, 2319-2335.

(85) Laws, E. A.; Taguchi, S.; Harata, J.; Pang, L. High algal production rates achieved in a shallow outdoor flume. Biotechnol. Bioeng. 1986, 28, 191-197.

(86) Laws, E. A.; Taguchi, S.; Harata, J.; Pang, L. Optimization of microalgal production in a shallow outdoor flume. Biotechnol. Bioeng. 1988, 32, 140-147.

(87) Lee, C.-G.; Palsson, B. Ø. High-density algal photobioreactors using light-emitting diodes. Biotechnol. Bioeng. 1994, 44, 11611167.

(88) Muller-Feuga, A.; Guédes, R. L.; Hervé, A.; Durand, P. Comparison of artificial light photobioreactors and other production systems using Porphyridium cruentum. J. Appl. Phycol. 1998, 10, $83-90$.

(89) Fuentes, M. M. R.; Sánchez, J. L. G.; Sevilla, J. M. F.; Fernández, F. G. A.; Pérez, J. A. S.; Grima, E. M. Outdoor continuous culture of Phorphyridium cruentum in a tubular photobioreactor: quantitative analysis of the daily cyclic variation of culture parameters. $J$. Biotechnol. 1999, 70, 271-288.

(90) Fernández, A. F. G.; Sevilla, J. M. F.; Pérez, J. A. S.; MolinaGrima, E.; Chisti, Y. Airlift-driven external-loop tubular photobioreactors for outdoor production of microalgae: assessment of design and performance. Chem. Eng. Sci. 2001, 56, 2721-2732.

(91) Marsot, P.; Fournier, R.; Blais, C. Culture à dialyse: emploi de fibres creuses dialysantes pour la culture massive de phytoplankton. Can. J. Fish. Aquat. Sci. 1981, 38, 905-911.

(92) Camacho, F. G.; Gómez, A. C.; Fernández, F. G. A.; Sevilla, J. F.; Grima, E. M. Use of concentric-tube airlift photobioreactors for microalgal outdoor mass cultures. Enzyme Microb. Technol. 1999, $24,164-172$.

(93) Heussler, P.; Castillo, S. J.; Merino, M. F.; Vasquez, V. V. Improvements in pond construction and $\mathrm{CO}_{2}$ supply for the mass production of microalgae. Arch. Hydrobiol. Beih. Ergebn. Limnol. 1978, 11, 254-258.

(94) Sánchez, J. L. G.; Berenguel, M.; Rodríguez, F.; Sevilla, J. M. F.; Alias, C. B.; Fernández, F. G. A. Minimization of carbon losses in pilot-scale outdoor photobioreactors by model-based predictive control. Biotechnol. Bioeng. 2003, 84, 533-543.

(95) Berenguel, M.; Rodríguez, F.; Acién, F. G.; García, J. L. Model predictive control of $\mathrm{pH}$ in tubular photobioreactors. J. Process Control 2004, 14, 377-387.

(96) Oswald, W. J. Large-scale algal culture systems (engineering aspects). In Micro-Algal Biotechnology; Borowitzka, M. A., Borowitzka, L. J., Eds.; Cambridge University Press: New York, 1988; pp 357-394.

(97) Camacho, F. G.; Gómez, A. C.; Sobczuk, T. M.; Grima, E. M. Effects of mechanical and hydrodynamic stress in agitated, sparged cultures of Porphyridium cruentum. Process Biochem. 2000, 35, $1045-1050$.

(98) Singh, G. Reactor design for plant cell culture of food ingredients and additives. Food Technol. 1997, 51, 62-66.

(99) Degen, J.; Uebele, A.; Retze, A.; Schmid-Staiger, U.; Trösch, W. A novel airlift photobioreactor with baffles for improved light utilization through the flashing light effect. J. Biotechnol. 2001, 92, 89-94.

(100) Laws, E. A.; Taguchi, S.; Hirata, J.; Pang, L. Continued studies of high algal productivities in a shallow flume. Biomass 1987, 11, $39-50$.

(101) Pirt, S. J.; Lee, Y. K.; Richmond, A.; Watts-Pirt, M. The photosynthetic efficiency of Chlorella biomass growth with reference to solar energy utilization. J. Chem. Technol. Biotechnol. 1980, 30, $25-34$.

(102) Sandnes, J. M.; Ringstad, T.; Wenner, D.; Heyerdahl, P. H.; Källqvist, T.; Gislerød, H. R. Real-time monitoring and automatic density control of large-scale microalgal cultures using near infrared (NIR) optical density sensors. J. Biotechnol. 2006, 122, 209-215.

(103) Dubinsky, Z.; Matsukawa, R.; Karube, I. Photobiological aspects of algal mass culture. J. Mar. Biotechnol. 1985, 2, 61-65.

(104) Evers, E. G. A model for light-limited continuous culturesgrowth, shading, and maintenance. Biotechnol. Bioeng. 1991, 38, 254-259.

(105) You, T.; Barnett, S. M. Effect of light quality on production of extracellular polysaccharides and growth rate of Porphyridium cruentum. Biochem. Eng. J. 2004, 19, 251-258.

(106) Simmer, J.; Tichy, V.; Doucha, J. What kind of lamp for the cultivation of algae? J. Appl. Phycol. 1994, 6, 309-313.

(107) Li, J.; Xu, N. S.; Su, W. W. Online estimation of stirred-tank microalgal photobioreactor cultures based on dissolved oxygen measurement. Biochem. Eng. J. 2003, 14, 51-65.

(108) Hejazi, M. A.; Wijffels, R. H. Milking of microalgae. TIBTECH 2004, 22, 189-194. 